\title{
Endogenously Released Neuropeptide Y Suppresses Hippocampal Short-Term Facilitation and Is Impaired by Stress-Induced Anxiety
}

\author{
(1) Qin Li, ${ }^{\circ}$ Aundrea F. Bartley, and $\oplus_{\text {Lynn E. Dobrunz }}$ \\ Department of Neurobiology, Civitan International Research Center, and Evelyn F. McKnight Brain Institute, University of Alabama at Birmingham, \\ Birmingham, Alabama 35294
}

Neuropeptide Y (NPY) has robust anxiolytic properties and is reduced in patients with anxiety disorders. However, the mechanisms by which NPY modulates circuit function to reduce anxiety behavior are not known. Anxiolytic effects of NPY are mediated in the CA1 region of hippocampus, and NPY injection into hippocampus alleviates anxiety symptoms in the predator scent stress model of stress-induced anxiety. The mechanisms that regulate NPY release, and its effects on CA1 synaptic function, are not fully understood. Here we show in acute hippocampal slices from mice that endogenous NPY, released in response to optogenetic stimulation or synaptically evoked spiking of NPY + cells, suppresses both of the feedforward pathways to CA1. Stimulation of temporoammonic synapses with a physiologically derived spike train causes NPY release that reduces short-term facilitation, whereas the release of NPY that modulates Schaffer collateral synapses requires integration of both the Schaffer collateral and temporoammonic pathways. Pathway specificity of NPY release is conferred by three functionally distinct NPY + cell types, with differences in intrinsic excitability and short-term plasticity of their inputs. Predator scent stress abolishes the release of endogenous NPY onto temporoammonic synapses, a stress-sensitive pathway, thereby causing enhanced short-term facilitation. Our results demonstrate how stress alters CA1 circuit function through the impairment of endogenous NPY release, potentially contributing to heightened anxiety.

Key words: hippocampus; interneuron; predator scent stress; Schaffer collateral; short-term plasticity; temporoammonic

\section{Significance Statement}

Neuropeptide Y (NPY) has robust anxiolytic properties, and its levels are reduced in patients with post-traumatic stress disorder. The effects of endogenously released NPY during physiologically relevant stimulation, and the impact of stress-induced reductions in NPY on circuit function, are unknown. By demonstrating that NPY release modulates hippocampal synaptic plasticity and is impaired by predator scent stress, our results provide a novel mechanism by which stress-induced anxiety alters circuit function. These studies fill an important gap in knowledge between the molecular and behavioral effects of NPY. This article also advances the understanding of NPY + cells and the factors that regulate their spiking, which could pave the way for new therapeutic targets to increase endogenous NPY release in patients in a spatially and temporally appropriate manner.

\section{Introduction}

Neuropeptide Y (NPY) is an endogenous neuropeptide with robust anxiolytic properties (Eaton et al., 2007). Low levels of NPY

Received Aug. 15, 2016; revised Sept. 30, 2016; accepted 0ct. 18, 2016.

Author contributions: Q.L., A.F.B., and L.E.D. designed research; Q.L. and A.F.B. performed research; Q.L. and A.F.B. analyzed data; Q.L., A.F.B., and L.E.D. wrote the paper.

This research was supported by National Institutes of Health Grant R01-MH-108342 and a University of Alabama Center for Clinical \& Translational Sciences Pilot Award to L.E.D. We thank Drs. Lori McMahon, Linda OverstreetWadiche, Farah Lubin, and Vladimir Parpura for helpful comments on the manuscript.

The authors declare no competing financial interests.

Correspondence should be addressed to Lynn E. Dobrunz, University of Alabama at Birmingham, 1825 University Boulevard, SHEL 902, Birmingham, AL 35294. E-mail: dobrunz@uab.edu.

DOI:10.1523/JNEUROSCI.2599-16.2016

Copyright $\odot 2017$ the authors $\quad 0270-6474 / 17 / 370023-15 \$ 15.00 / 0$ have been measured in patients with post-traumatic stress disorder (PTSD; Reichmann and Holzer, 2016), and in rodents with the predator scent stress model of stress-induced anxiety/PTSD (Cohen et al., 2012). Importantly, NPY is considered a "stress resilience factor" (Cohen et al., 2012; Reichmann and Holzer, 2016), and NPY enhancement is proposed as a potential therapy for multiple anxiety disorders (Heilig, 2004; Harro, 2006; Sah and Geracioti, 2013).

Hippocampal dysfunction has been implicated in anxiety disorders (Eaton et al., 2007; Goosens, 2011), which are considered a maladaptive form of learning. NPY is expressed at high levels in hippocampus (Eaton et al., 2007), even higher than in amygdala (Cohen et al., 2012). Notably, predator scent stress reduces NPY 
levels in hippocampus more than in amygdala, and hippocampal injections of NPY alleviate the resulting anxiety symptoms (Cohen et al., 2012). NPY is particularly high in CA1 (Pickel et al., 1995; Nakamura et al., 2011), an area important for aversive memory formation (Engin and Treit, 2007; Hirsch et al., 2015), and direct injection of NPY into CA1 produces anxiolytic effects in rodents (Smiałowska et al., 2007). The effects of NPY on CA1 function are therefore important for anxiolytic properties, although the mechanisms by which NPY alters CA1 circuit function to modulate anxiety are not well understood.

The two main inputs to CA1, the Schaffer collateral (SC) and temporoammonic (TA) pathways, have both been implicated in anxiety and fear learning (Kallarackal et al., 2013; Lovett-Barron et al., 2014; Zhang et al., 2014; Broussard et al., 2016). SC and TA inputs each provide excitation to NPY + GABAergic feedforward interneurons in CA1 (Price et al., 2005; Milstein et al., 2015); however, the role of NPY release in these pathways is not yet known. NPY release is controlled by the pattern of synaptically evoked spiking of NPY + interneurons, which depends on the intrinsic excitability of NPY + cells and on the short-term plasticity of their excitatory inputs. Two morphological types of $\mathrm{NPY}+$ interneurons have been identified in stratum radiatum (SR) and stratum lacunosum-moleculare (SLM), the Ivy cells and neurogliaform cells, respectively (Fuentealba et al., 2008; Somogyi et al., 2012; Overstreet-Wadiche and McBain, 2015). Neurogliaform cells have axonal arbors in SLM (Price et al., 2005; Bezaire and Soltesz, 2013), and Ivy cells have axonal arbors primarily in SR (Somogyi et al., 2012; Bezaire and Soltesz, 2013). As a result, NPY released by these two cell subtypes could modulate TA and SC synapses, respectively. Bath-applied NPY has been shown to inhibit glutamate release from SC synapses onto CA1 pyramidal cells (Colmers et al., 1987; Qian et al., 1997), while the effects of NPY on TA synapses remain to be demonstrated. In addition, the impact on SC or TA synapses of endogenously released NPY in response to temporally complex input patterns (Dobrunz and Stevens, 1999) is not known.

Here we demonstrate that endogenous NPY, released in response to stimulation with a physiologically derived spike train, suppresses short-term facilitation of both CA1 feedforward pathways. NPY release is pathway specific, and the release of NPY that modulates SC synapses requires combined SC and TA stimulation. We investigate the factors that differentially regulate the spiking of NPY + cells, and thus govern the pathway specificity of NPY release, including intrinsic excitability and short-term plasticity. Finally, we use the predator scent stress model to show that the release of endogenous NPY is abolished by stress-induced anxiety. This causes enhanced short-term plasticity of TA synapses, potentially contributing to prolonged anxiety.

\section{Materials and Methods}

\section{Animals}

The majority of experiments used either C57BL/6J mice (RRID: IMSR_JAX:000664) or NPY-hrGFP mice (B6.FVB-Tg(Npy-hrGFP) 1 Lowl/J; RRID: IMSR_JAX:006417). For optogenetic experiments, NPY Channelrhodopsin-2 (ChR2) was expressed in NPY + cells by crossing NPY-cre mice (Tg (Npy-cre)RH26Gsat/Mmucd, Mutant Mouse Regional Resource Center, University of Rochester, Rochester, NY; RRID: MMRRC_034810-UCD; Gong et al., 2003, 2007) with ChR2/EYFP mice (Ai32 (RCL-ChR2 (H134R)/EYFP; RRID: IMSR_JAX:012569; Madisen et al., 2012). The NPY-hrGFP mice were maintained on a C57BL/6J background. The NPY-ChR2 mice were maintained on a mixed background. All mice were housed in a room kept at $26 \pm 2^{\circ} \mathrm{C}$, with food and water available ad libitum. The room maintained a standard $12 \mathrm{~h}$ light/ dark cycle. Animals were housed with the whole litter until weaned [post- natal day 21 (P21) to P22]. Weaned animals were housed with no more than five mice in a cage, except for animals used for behavioral testing, which were individually housed upon separation.

\section{Hippocampal slice preparation}

Acute hippocampal slices were made from male and female mice (18-25 postnatal days, unless otherwise noted) as described previously (Bartley and Dobrunz, 2015). Briefly, mice were anesthetized with isoflurane and then decapitated using a guillotine. Brains were removed rapidly, and $400-\mu \mathrm{m}$-thick coronal slices were cut using a vibrating microtome (VT1000S, Leica). Slicing was performed in ice-cold $\left(1-3^{\circ} \mathrm{C}\right)$ dissecting solution containing the following (in $\mathrm{mM}$ ): $120 \mathrm{NaCl}, 3.5 \mathrm{KCl}, 0.7 \mathrm{CaCl}_{2}$, $4.0 \mathrm{MgCl}_{2}, 1.25 \mathrm{NaH}_{2} \mathrm{PO}_{4}, 26 \mathrm{NaHCO}_{3}$, and 10 glucose, bubbled with $95 \% \mathrm{O}_{2} / 5 \% \mathrm{CO}_{2}$, pH 7.35-7.45. The CA3 region of the hippocampus was removed to prevent recurrent excitation. Slices were stored at room temperature in a holding chamber containing the dissecting solution and bubbled with $95 \% \mathrm{O}_{2} / 5 \% \mathrm{CO}_{2}$ for $>1$ h before recording.

\section{Electrophysiology}

Slices were held in a submersion recording chamber perfused with external recording solution (ERS) composed of the following (in $\mathrm{mm}$ ): 120 $\mathrm{NaCl}, 3.5 \mathrm{KCl}, 2.5 \mathrm{CaCl}_{2}, 1.3 \mathrm{MgCl}_{2}, 1.25 \mathrm{NaH}_{2} \mathrm{PO}_{4}, 26 \mathrm{NaHCO} 3$, and 10 glucose. The solution was bubbled with $95 \% \mathrm{O}_{2}$, with $\mathrm{pH} 7.35-7.45$. Experiments were performed at $28-30^{\circ} \mathrm{C}$. In all experiments, picrotoxin (100 $\mu \mathrm{M} ; \mathrm{Abcam})$ was added to the external solution to block inhibitory synaptic responses mediated by $\mathrm{GABA}_{\mathrm{A}}$ receptors. Aminophosphonovalerate $(100 \mu \mathrm{M})$ was added to block NMDA receptor-mediated currents and to prevent long-term synaptic plasticity. BIBP-3226 and BIIE-0246 (Tocris Bioscience) were used to block NPY Y1 and Y2 receptors, respectively. BIIE-0246 was dissolved in DMSO; the final DMSO concentration for experiments was $0.01 \%$. All electrophysiology data were recorded and analyzed using custom software written in Visual Basic version 6.0.

Extracellular stimulation. Extracellular stimulation of SC axons or TA axons was applied using a bipolar tungsten microelectrode (FHC). The independence of TA and SC stimulation has previously been demonstrated under similar recording conditions (Speed and Dobrunz, 2009). Stimulation was generated from a Master-8-cp stimulator (A.M.P.I.) and applied with a BSI-2 biphasic stimulus isolator (BAK Electronics). Stimulus intensity ranged from 20 to $150 \mu \mathrm{A}$, and stimulus duration was $100 \mu \mathrm{s}$.

Field potential recordings. Dendritic field EPSPs (fEPSPs) were recorded using glass micropipettes (2-5 M $\Omega$ ) filled with ERS. SC dendritic fEPSPs were recorded in SR in response to extracellular stimulation of SC axons, and TA fEPSPs were recorded in SLM in response to extracellular stimulation of TA axons. The initial slope of the fEPSP was used as a measure of synaptic response, except in Figure 2, where the amplitude of the fEPSP was measured. For both pathways, the stimulation intensity was set as $50 \%$ of the maximum synaptic response (defined as the largest fEPSP before population spikes are generated).

Whole-cell recording. NPY + interneurons expressing GFP were identified visually in SR and SLM of CA1 using infrared differential inference contrast optics and epifluorescent optics on a Nikon E600FN upright microscope. NPY + interneurons were recorded in voltage-clamp mode for EPSCs and in current-clamp mode for the measurement of intrinsic excitability. Cell-attached recording mode was used for synaptically evoked spiking experiments.

For EPSC recordings, NPY + interneurons were patched and recorded at a holding potential of $-60 \mathrm{mV}$ using an Axopatch 200B amplifier (Molecular Devices). Patch electrodes (3-6 M $\Omega$ ) were filled with a cesium gluconate-based internal solution composed of the following (in mM): 120 Cs-gluconate, 0.6 EGTA, 5 MgCl2, 25 HEPES, 5 QX-314, 10 ATP, and 0.3 GTP. $\mathrm{pH}$ was adjusted to 7.2 with $\mathrm{CsOH}$. The access resistance and holding current $(<200 \mathrm{pA})$ were monitored continuously. Recordings were rejected if either access resistance or holding current increased $\geq 20 \%$ during the experiment. EPSCs were recorded in NPY+ Ivy cells with somata in SR in response to SC stimulation or TA stimulation. EPSCs were recorded in NPY+ neurogliaform cells located in SLM in response to TA stimulation. EPSCs in neurogliaform cells in response to SC stimulation have previously been shown to be extremely small 
(Price et al., 2005) and, therefore, were not investigated here. For both pathways, the stimulation intensity was set to obtain a response that $50 \%$ of the maximum synaptic response (before the onset of polysynaptic EPSCs).

In synaptically evoked spiking and intrinsic excitability experiments, interneurons were recorded using a potassium gluconate-based internal solution containing the following (in mM): $150 \mathrm{~K}$-gluconate, 0.1 EGTA, 3 $\mathrm{NaCl}, 6 \mathrm{KCl}, 10 \mathrm{HEPES}, 10 \mathrm{ATP}$, and $0.3 \mathrm{GTP}$. $\mathrm{pH}$ was adjusted to 7.2 with $\mathrm{KOH}$. Synaptically evoked spiking experiments used extracellular stimulation of SC or TA pathways, and the stimulus intensity was set to generate a baseline spike probability of $\sim 0.8$ for Ivy-paired-pulse depression (PPD) cells, and $\sim 0.25-0.3$ for Ivy-paired-pulse facilitation (PPF) and NGF cells. The baseline spike probability was set low for the Ivy-PPF and NGF cells to enable the short-term facilitation of spiking to be shown, and set high for Ivy-PPD cells to enable the short-term depression of spiking to be shown. Cells in stratum radiatum were initially classified as Ivy-PPF or Ivy-PPD cells based on the paired-pulse ratio of spiking in response to the stimulation of the SC pathway during baseline. For TA synaptically evoked spiking onto stratum radiatum NPY+ interneurons, the spike probability was set to $\sim 0.25$ to allow facilitation to be seen. Synaptically-evoked spiking was measured using cell-attached patch recordings. After repeating the physiologically derived spike train (PST) pattern 6-10 times, the cell membrane was ruptured, and the cell recorded in whole-cell voltage clamp to record the paired-pulse ratio of EPSCs and to confirm the short-term plasticity of the NPY+ cells.

Intrinsic excitability was measured at holding potential of $-60 \mathrm{mV}$. $600 \mathrm{~ms}$ current steps $(0-400 \mathrm{pA}$, in $50 \mathrm{pA}$ intervals) were applied every $8 \mathrm{~s}$, and the initial firing frequency (based on interval between the first three spikes) and total number of spikes were measured. After measuring spiking, the paired-pulse ratios of EPSCs were recorded to confirm the short-term plasticity of the NPY+ interneurons.

The phenomenon of persistent firing (Krook-Magnuson et al., 2011; Sheffield et al., 2011) was assessed by applying a $20 \mathrm{~Hz}$ constant frequency train of current steps ( $1500 \mathrm{pA}, 2 \mathrm{~ms}$ ) for $1 \mathrm{~min}$, and recording without stimulation for an additional $10 \mathrm{~min}$. The criterion for persistent firing was the persistence of action potential activity for at least $30 \mathrm{~s}$ after the end of stimulation. Persistent firing typically lasted 1-10 min.

Paired-pulse stimulation. Paired-pulse stimulation with different intervals (in ms: $40,60,100,200$, and 500) was applied in a pseudorandom sequence and repeated for a minimum of 10 times at $0.1 \mathrm{~Hz}$. The averaged paired-pulse ratio (EPSC2/EPSC1 or fEPSP2/fEPSP1) was calculated after recording.

Physiologically derived spike train. Stimulation was also applied using a PST pattern; details of the methods used for the PST experiments have been described previously (Dobrunz and Stevens, 1999; Dekay et al., 2006; Speed and Dobrunz, 2009; Sun et al., 2009). Briefly, patterns of action potential timing that were recorded in vivo from a CA3 pyramidal cell were used to reflect the temporal complexity of input patterns that hippocampal synapses receive in vivo. A subset of experiments (data not shown) used a spike pattern taken from in vivo recording of action potential timing from a pyramidal cell in entorhinal cortex layer III. These spike patterns were provided by Dr. György Buzsáki (New York University, New York, NY) (Isomura et al., 2006). In each PST experiment, a pattern of 66 points was presented 3-7 times for EPSC and fEPSP experiments, and 7-15 times for spiking experiments, separated by control sections of 15-25 points at a slow constant frequency. For the majority of experiments, the stimulation during the control period was at $0.08 \mathrm{~Hz}$; however, $0.1 \mathrm{~Hz}$ stimulation was used for the control period of the spiking experiments. The data for each cell are normalized by the average value of the last 10 points of the control period. The normalized responses are plotted against stimulus number rather than time to better visualize the short-term plasticity that was occurring. The stimulus amplitude and duration were held constant during each experiment.

The CA3-derived PST incorporates stimulation intervals ranging from $30 \mathrm{~ms}$ to $23.6 \mathrm{~s}$. The entorhinal cortex-derived PST incorporates stimulation intervals ranging from $12 \mathrm{~ms}$ to $4.02 \mathrm{~s}$. For whole-cell and cellattached experiments using the PST pattern, the instantaneous frequency was calculated for each interval. The responses from at least four intervals with similar frequencies were binned together to generate the graphs in Figures $4 F, 5 D$, and $6 E$.

NPY release assay. To test for the effects of endogenously released NPY on synaptic responses, PST stimulation was applied, and fEPSPs from SC or TA synapses were compared without (control) and with (NPYR antagonists) application of $1 \mu \mathrm{M}$ BIBP3226 and $1 \mu \mathrm{M}$ BIIE0246 to block NPY Y1 and Y2 receptors, respectively. The criteria for the detection of NPY release is as follows:

Avg. norm. $\mathrm{fEPSP}_{\mathrm{NPY} \text { antagonists }}-$ avg. norm. $\mathrm{fEPSP}_{\text {control }}>0.05$.

The stimulation intensity used for SC and TA stimulation in the NPY release assay was not different $(56.3 \pm 16.3$ vs $68.9 \pm 9.2 \mu \mathrm{A}, t$ test, $p=$ $0.48)$. Additionally, the stimulation intensity of the TA pathway used for experiments that induced and did not induce NPY release was similar $(68.9 \pm 9.2$ vs $72.5 \pm 11.1 \mu \mathrm{A}$, Student's $t$ test, $p=0.82)$.

To test for the possible effects of repeated application of the PST on NPY release, we compared the first and third repetitions of the control PST, but saw no difference in the average response for either SC pathways ( $1.52 \pm 0.3$ vs $1.39 \pm 0.19$, paired $t$ test, $p=0.17)$ or TA pathways ( $1.23 \pm$ 0.09 vs $1.20 \pm 0.08$, paired $t$ test, $p=0.16$ ). Additionally, there was no change in the average of the normalized TA fEPSP slopes during the PST with $0.01 \%$ DMSO $(1.24 \pm 0.13$ vs $1.27 \pm 0.13$, paired $t$ test, $p=0.12$ $n=4)$.

Photoactivation of NPY + interneurons. Experiments were performed using slices from male and female NPY-ChR2 mice at 7-9 weeks of age to ensure adequate time for recombination. Optogenetic experiments were performed using a Zeiss Axio Examiner.A1 microscope. NPY + neurons expressing ChR2 were photostimulated using pulses of blue light (470 $\mathrm{nm}$ ) generated by a Colibri.2 LED Light Source (Zeiss) applied to CA1 in acute hippocampal slices through a $40 \times$ water-immersion objective, resulting in an illumination area of $0.32 \mathrm{~mm}^{2}$. The Colibri.2 was triggered by a Master-9 digital stimulator (A.M.P.I).

NPY release was elicited by high-frequency trains of photostimulation (trains of 25 pulses at $50 \mathrm{~Hz}$, pulse duration $6 \mathrm{~ms}$ ). We first recorded from $\mathrm{NPY}+$ interneurons to confirm action potential generation upon ChR2 activation and determined that a pulse duration of $6 \mathrm{~ms}$ was needed to maintain firing throughout the train (data not shown). The effects of NPY release on excitatory inputs to CA1 pyramidal cells were tested by recording fEPSPs in response to low-frequency electrical stimulation in the TA pathway or SC pathway. Electrical stimulation was generated from a Master-9 digital stimulator (A.M.P.I.) and applied with a BSI-2 biphasic stimulus isolator (BAK Electronics). The stimulus intensity was set to obtain a synaptic response that was $30-40 \%$ of the maximum fEPSP. To ensure that observed effects were not due to GABA release from NPY + interneurons, $\mathrm{GABA}_{\mathrm{A}}$ receptor-mediated inhibition was blocked using $100 \mu \mathrm{m}$ picrotoxin. Electrical stimulation was applied at a low frequency $(0.03 \mathrm{~Hz})$ to ensure that the electrical stimulation did not induce NPY release, and the $50 \mathrm{~Hz}$ train of blue light was applied at 0.01 Hz. To measure the duration of the effects of NPY released by photostimulation, a variable delay $(0,20,50,100,500$, and $1000 \mathrm{~ms})$ was applied between the end of the $50 \mathrm{~Hz}$ train and the electrical stimulation (see Fig. 3B). Each set of intervals was repeated three to four times, with a period of rest of at least $7 \mathrm{~min}$ between sets to allow for the recovery of releasable NPY. To test for the effects of multiple cycles of photoactivation, we compared the responses at $0 \mathrm{~ms}$ (no delay) from the first and third cycles. There was no difference in the response to the first and third cycle for TA synapses $(83.4 \pm 2.8 \%$ vs $83.3 \pm 3.3 \%$, paired $t$ test, $p=$ $0.94)$, indicating no reduction in the amount of NPY released. In contrast, for SC synapses the effect of photostimulation was reduced on the third cycle, indicating that less NPY was released $(45.1 \pm 4.3 \%$ vs $64.6 \pm$ $4.8 \%$, paired $t$ test, $p<0.05$ ). Light intensity was either $25 \%$ or $100 \%$ of maximum; no differences were observed, so data from the two light intensities were pooled. The reduction of the fEPSP by activation of ChR2 was blocked by NPY receptor (NPYR) antagonists (see Fig. 3C; TA: $94.3 \pm 3.7 \%, n=5$; SC: $80.4 \pm 5.5 \%, n=6$ ), confirming that it was caused by endogenously released NPY. 

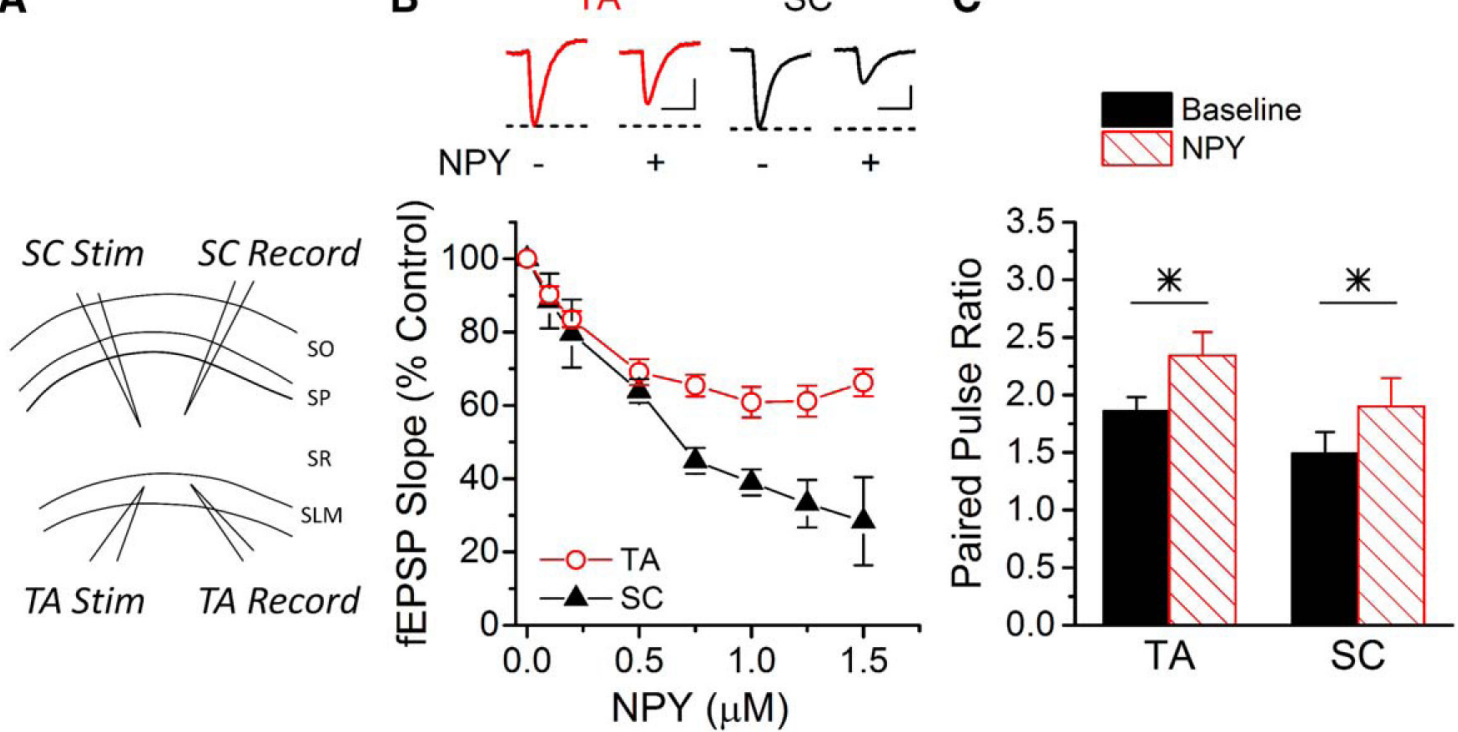

Figure 1. Bath-applied NPY affects both SC and TA synapses onto CA1 pyramidal cells. $A$, A schematic showing field potential recordings (Record) from SR and SLM layers in response to SC or TA stimulation (Stim), respectively. B, Exogenous NPY decreases the synaptic response size in both TA and SC pathways (two-way ANOVA, $F_{(7.46)}=21.57, p<0.05 ; n=4 / 4$, respectively). However, the SC fEPSPs plateau at a lower level than TA (two-way ANOVA, $F_{(1,46)}=8.37, p<0.05 ; n=4 / 4$, respectively). Insets, Example traces of TA (left) and SC (right) fEPSPs without and with NPY (1.5 $\mu \mathrm{M})$. Calibration: TA, $0.1 \mathrm{mV}, 20 \mathrm{~ms} ; \mathrm{SC}, 0.2 \mathrm{mV}, 20 \mathrm{~ms}$. C, The paired-pulse ratio at a $50 \mathrm{~ms}$ interval significantly increased after applying $1.5-2 \mu \mathrm{m}$ NPY at both TA synapses $(n=4$; paired $t$ test, $p<0.05)$ and SC synapses $(n=4$; paired $t$ test, $p<0.05)$ onto CA1 pyramidal cells. SO, stratum oriens; SP, stratum pyramidale.

\section{Behavior}

Animals. Behavioral experiments were conducted on 4-week-old male C57BL/6J mice. All behavioral experiments were performed during the light cycle. A total of 15-18 animals/group were used, based on a power analysis with $p>0.7$. Animals were randomly assigned to the two treatment groups. The experimenter was not blind to treatment groups.

Predator scent stress. Predator scent stress was induced using two exposures to TMT (2,5-dihydro-2,4,5-trimethylthiazoline; Contech), a chemical from fox feces that elicits a fear response in rodents (Fendt and Endres, 2008; Rosen et al., 2015). Animals were singly housed following weaning, habituated to housing conditions for $2 \mathrm{~d}$, and handled for $3 \mathrm{~d}$ before testing. On the day before TMT exposure, animals were transported to the testing room for habituation, which involved moving them into a new cage and placing them in a fume hood for $30 \mathrm{~min}$. On the testing day, mice were brought to the testing room and transferred to prepared cages in the fume hood. These cages were cleaned with distilled water and ethanol, and filled with $100 \mathrm{~g}$ of fresh bedding. In each cage, a $50 \mathrm{ml}$ conical tube holding a piece of Kimwipe was attached to one side. Mice were allowed to explore the cage for $5 \mathrm{~min}$, and then $38.8 \mu \mathrm{l}$ of 7.7 M TMT stock (Day et al., 2004; $300 \mu \mathrm{mol}$, TMT group) or distilled water (vehicle group) was applied onto the Kimwipe. Mice remained in the cage for $20 \mathrm{~min}$, and then were returned to their home cages. TMT or vehicle exposure was repeated $7 \mathrm{~d}$ later.

Elevated plus maze. Anxiety behavior was measured using the elevated plus maze $7 \mathrm{~d}$ after the second TMT exposure. The elevated plus maze is a cross Plexiglas platform that is $1 \mathrm{~m}$ high with two open arms and two closed arms (Med Associates). For each experiment, mice were placed on the center of the platform and allowed free exploration for $5 \mathrm{~min}$. Behavior assessments include time in open and closed arms and on the central platform; the number of open and closed arm entries; and total exploration (entries into all arms), measured using an automatic video-tracking system (Med Associates). Anxiety index (Cohen et al., 2012) was used as a measure that integrates data from the elevated plus maze and was calculated as follows:

Anxiety index

$=1-\frac{\left(\frac{\text { Time spent in open arms }}{\text { Total time }}+\frac{\text { Number of entries to open arms }}{\text { Total entries }}\right)}{2}$.

\section{Measurement of plasma NPY}

In a subset of animals, blood was taken to measure plasma NPY levels before and after behavioral testing. Blood was taken via tail bleed 1 week before weaning, and trunk blood was taken following decapitation by guillotine at the time of electrophysiology studies. Blood was centrifuged $\left(2000 \times g\right.$ for $15 \mathrm{~min}$ at $\left.4^{\circ} \mathrm{C}\right)$ immediately after collection. Plasma was collected and stored at $-20^{\circ} \mathrm{C}$. NPY plasma levels were measured with a NPY ELISA kit (catalog \#EZRMNPY-27K, Millipore) following the instructions of the manufacturer. The sensitivity of the NPY assay is 0.004 $\mathrm{ng} / \mathrm{ml}$, and the within-assay variation is $<15 \%$. All samples were measured in duplicate. The behavioral data from these animals were not different from that of the animals in which plasma NPY levels were not measured (two-way ANOVA, $F_{(1,41)}=1.87, p=0.18$ ), so the data were pooled in the group data presented in Figure 8.

\section{Statistical analysis}

Data are presented as the mean \pm SEM. Statistical comparisons were made using the two-tailed Student's $t$ test, two-tailed paired $t$ test, and one-way or two-way ANOVA followed by Bonferroni post hoc test, as indicated in the figure legends. A $p$ value of $<0.05$ is considered to be significant and is indicated in figures by symbol ${ }^{*}$. In electrophysiological tests, $N$ means the number of slices in field potential experiments and the number of cells in whole-cell patch experiments. Each set of experiments includes at least three mice per group. In behavioral tests, $N$ means the number of mice.

\section{Results}

Exogenous NPY decreases the response of both TA and SC synapses onto CA1 pyramidal cells

Bath application of NPY decreased the fEPSP at SC synapses onto CA1 pyramidal cells (Fig. 1A,B), as previously shown (Colmers et al., 1988), with a maximum reduction to $\sim 28 \%$. Similarly, bath-applied NPY decreased the response of TA synapses in CA1 pyramidal cells, although the maximum fEPSP reduction was only to $\sim 60 \%$ (Fig. $1 A, B$ ). Exogenous NPY also increased the paired-pulse ratio at both SC and TA synapses (Fig. 1C). This shows that NPY reduces TA responses in pyramidal cells as well as SC responses, and suggests that the effects are presynaptic (Colmers et al., 1987). 

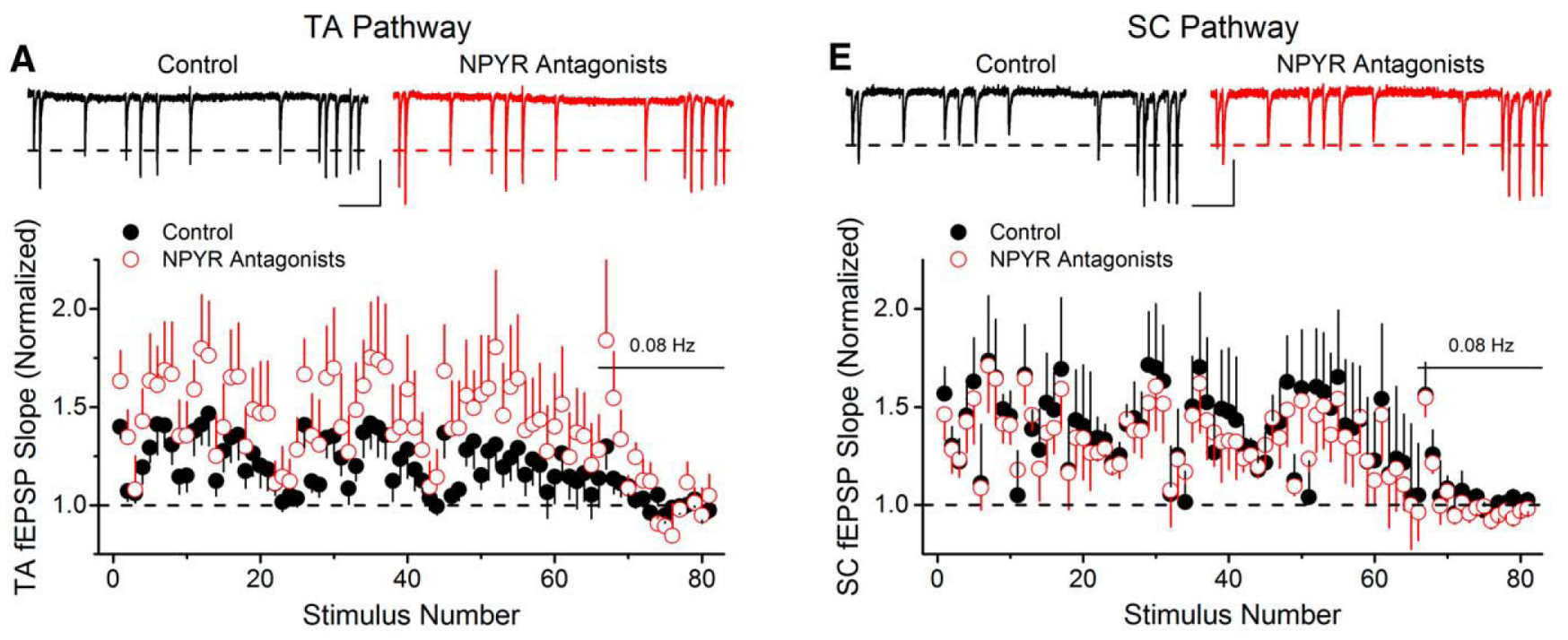
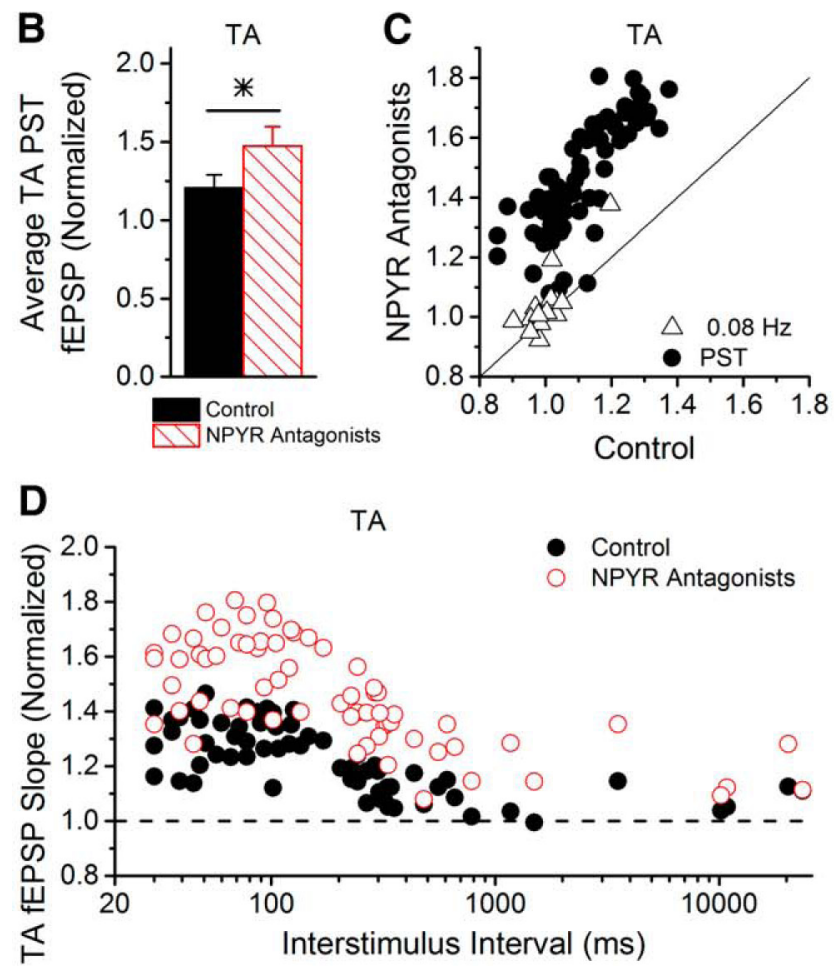
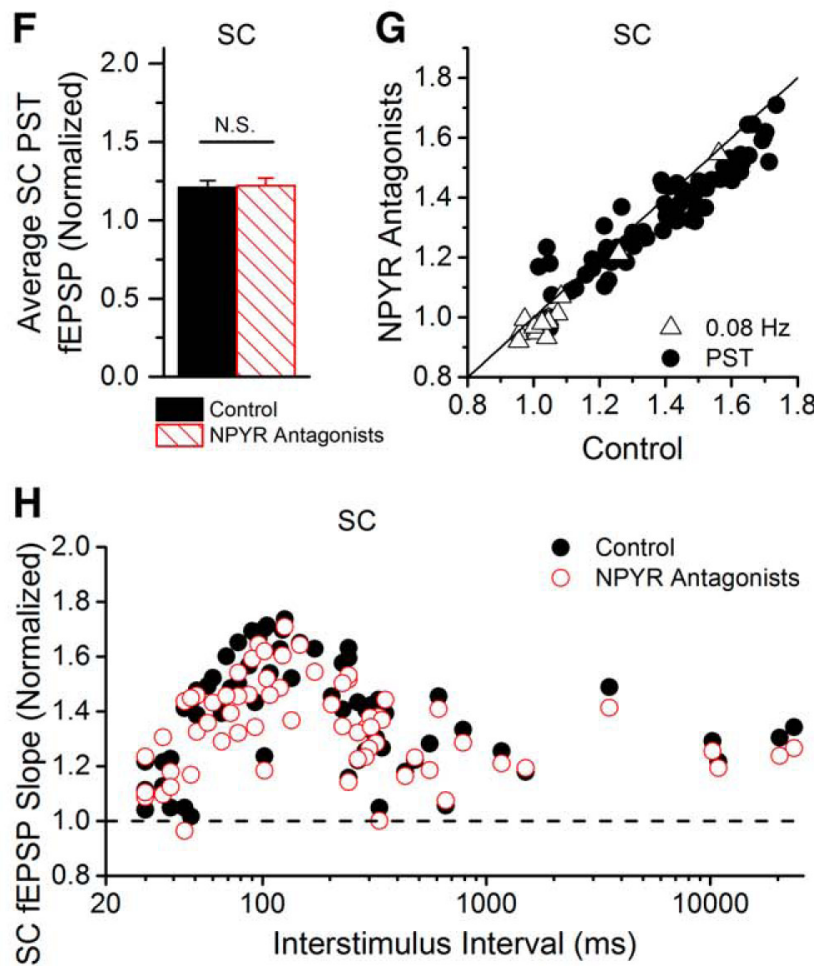

Figure 2. Endogenously released NPY is seen with TA stimulation but not with SC stimulation. A, During stimulation with a PST, group data show that endogenously released NPY alters short-term plasticity of TA synapses onto CA1 pyramidal cells. Blocking NPY Y1 and Y2 receptors (1 $1 \mu \mathrm{mBIBP} 3226$ and $1 \mu \mathrm{m}$ BIIE0246, respectively) increases the amount of short-term facilitation at TA synapses onto CA1 pyramidal cells (two-way ANOVA, $F_{(1,593)}=108.75, p<0.05 ; n=9$ ). Each PST is repeated three to five times during the control and application of NPYR antagonists. Responses are normalized to a 20 point control period ( $0.08 \mathrm{~Hz}$ constant frequency) applied at the end of each PST repetition. Inset, Example fEPSP traces from TA stimulation during $2.5 \mathrm{~s}$ of the PST pattern. Calibration: $0.4 \mathrm{mV}, 300 \mathrm{~ms}$. B, Blocking NPY Y1 and Y2 receptors increased the facilitation of TA fEPSPs during PST stimulation, causing an increase in the average normalized fEPSP ( $n=$ 9; paired $t$ test, $p<0.05)$. C, TA synaptic responses during the PST stimulation are plotted as control vs NPYR antagonists $(n=9)$, with the line at unity. The majority of PST responses are shifted upward, indicating increased facilitation when NPYRs are blocked. D, TA fEPSP responses without and with NPYR antagonists $(n=9)$ are plotted against the interstimulus interval during the PST. The PST pattern has interstimulus intervals ranging from $30 \mathrm{~ms}$ to $23.6 \mathrm{~s}$. E, Applying the same PST to SC synapses onto CA1 pyramidal cells does not change the short-term plasticity pattern in the presence of the NPY Y1 and Y2 receptor antagonists (two-way ANOVA, $F_{(1,593)}=1.88, p=0.17 ; n=5$ ). Inset, Example fEPSP traces from SC stimulation during 2.5 s of the PST pattern. Calibration: $0.4 \mathrm{mV}, 300 \mathrm{~ms}$. $\boldsymbol{F}-\boldsymbol{H}, \mathrm{SC}$ responses show no change during the PST stimulation with the application of the NPYR antagonists, shown three different ways $(n=5 ;$ paired $t$ test, $p=0.50)$.

Endogenously released NPY alters short-term plasticity of TA synapses onto CA1 pyramidal cells

Constant high-frequency stimulation has been shown to generate NPY release from hippocampal NPY + cells (Ledoux et al., 2009). To determine whether NPY can also be released by physiologically based stimulation (Dobrunz and Stevens, 1999), we used a PST to stimulate the TA or SC pathways, and measured the re- sulting short-term plasticity of the fEPSPs (Speed and Dobrunz, 2009). We compared short-term plasticity without (control) and with NPYRs blocked by Y1 and Y2 receptor antagonists (NPYR antagonists) to test for the effects of endogenously released NPY. Blocking NPYRs caused an increase in the short-term facilitation of TA responses to the PST in the majority of slices, thereby demonstrating the effects of NPY release [Fig. $2 A-D$; grouped 
data in 9 of 13 slices; only 4 of 13 slices had no effect with the addition of NPYR antagonists (1.23 \pm 0.16 vs $1.22 \pm 0.13)]$. There was an increase in the average amount of facilitation during the PST pattern with the application of NPYR antagonists (Fig. 2B). However, the baseline fEPSP was not affected by the washin of antagonists $(98.1 \pm 3.5 \% ; n=5$; paired $t$ test, $p=$ 0.61 ), indicating that the NPYRs are not tonically active in the slice. A point-by-point comparison of the responses in the antagonists to the control responses shows that blocking NPYRs alters the majority of responses during the PST (Fig. 2C). NPYR antagonists increase the facilitation of TA responses across a range of interstimulus intervals (Fig. 2D), indicating the long-lasting effects of released NPY. This effect of endogenously released NPY on TA synapses was confirmed using a PST pattern derived from action potential timing recorded in an entorhinal cortex layer III pyramidal cell (data not shown; six of nine slices; two-way ANOVA, $\left.F_{(1,899)}=108.42, p<0.05\right)$.

These data show that the release of endogenous NPY during PST stimulation inhibits glutamate release from TA synapses onto CA1 pyramidal cells, thus reducing synaptic short-term facilitation. This is the first demonstration that physiologically relevant stimulation can induce release of NPY and affect hippocampal short-term plasticity. In contrast, we saw no effect of NPYR antagonists at SC synapses onto pyramidal cells during PST stimulation in any slices (Fig. $2 E-H$ ). We tested multiple PST patterns (data not shown), including a higher-frequency pattern (up to $50 \mathrm{~Hz}$ ), but still could not detect the effects of endogenously released NPY in response to PST stimulation at SC synapses.

\section{Photoactivation of NPY interneurons elicits NPY release in both the TA and SC pathway}

Although bath-applied NPY modulates both TA and SC synapses, we see the effects of endogenously released NPY in response to PST stimulation at TA synapses on CA1 pyramidal cells, but not at SC synapses. To see whether directly activating NPY cells can cause NPY release that modulates SC synapses, we next induced the spiking of NPY + interneurons through photoactivation of ChR2 expressed in NPY + cells, using a constantfrequency train $(50 \mathrm{~Hz}, 25$ pulses; Fig. $3 A, B)$ to induce robust high-frequency spiking. The photostimulation train was followed by electrical stimulation of the TA or SC pathway (Fig. $3 A, B)$ to assess the effect on fEPSPs. A variable delay $(0-1000$ $\mathrm{ms}$ ) was applied between the end of the photostimulation train and the electrical stimulation, to determine the duration of the effects of NPY on synaptic function.

ChR2 activation induced NPY release that reduced the TA fEPSP response to $\sim 84 \%$ of the peak amplitude of interleaved controls (at 0 ms delay; Fig. $3 C, D$ ). The effect on SC synapses was even greater, with the SC fEPSP reduced to $~ 54 \%$ of control by ChR2 photoactivation ( 0 ms delay; Fig. $3 C, E$ ). The effects of photostimulation were blocked by NPYR antagonists (Fig. 3C), indicating that they were caused by endogenously released NPY. The released NPY still had effects out to $500 \mathrm{~ms}$ after the train for TA synapses (Fig. 3D), and out to $1000 \mathrm{~ms}$ after the train for SC synapses (Fig. $3 E$ ). This timing reflects the clearance of NPY, together with the duration of NPY-induced signaling cascades that modulate glutamate release. This is a much shorter duration than the effects of NPY on short-term facilitation in Figure 2D, which were seen at intervals as long as tens of seconds. These results suggest that NPY is no longer physically present to activate the receptors at the long interstimulus intervals, and that the effects of NPYR antagonists seen at longer intervals during the
PST are through indirect effects on short-term plasticity, which can last tens of seconds (Zucker and Regehr, 2002). Together, these data show that, when NPY + cells are driven to fire at high frequencies, endogenously released NPY is able to modulate SC synapses as well as TA synapses.

\section{Excitatory inputs to NPY interneurons elicit different short-term plasticity patterns}

Because SC synapses are modulated by endogenously released NPY in response to photostimulation, this suggests that PST stimulation of SC synapses alone does not induce enough spiking of NPY + cells to cause NPY release. We hypothesized that the difference between pathways could be due to distinct properties of the NPY + interneurons and their synaptic inputs. Short-term plasticity of TA inputs to neurogliaform cells during gamma frequency stimulation has been reported previously (Price et al., 2005); however, little is known about short-term plasticity of excitatory inputs onto Ivy cells. Furthermore, nothing is known about synaptically evoked spiking of Ivy and neurogliaform cells, or the short-term plasticity of their inputs, in response to temporally complex input patterns such as are received in vivo (Dobrunz and Stevens, 1999).

We therefore tested whether there are differences in the short-term plasticity of the excitatory inputs onto NPY + neurogliaform and Ivy interneurons that could contribute to the differences in NPY release between TA and SC stimulation. To identify $\mathrm{NPY}+$ cells for recording, we used NPY-hrGFP mice (van den Pol et al., 2009; Tricoire et al., 2010), in which NPY + interneurons have been classified in SR as Ivy cells and in SLM as neurogliaform cells (Tricoire et al., 2010). We recorded EPSCs in neurogliaform cells in response to TA stimulation (Price et al., 2005), because the majority of the dendrites from neurogliaform cells are located in SLM (Overstreet-Wadiche and McBain, 2015). We first measured EPSCs in Ivy cells in response to SC stimulation (Szabo et al., 2012), since the majority of the dendrites from Ivy cells are located in SR, although they can extend into SLM (Somogyi et al., 2012).

We find that TA synapses onto neurogliaform cells have robust PPF (Fig. 4A). In contrast, NPY + Ivy cells are heterogeneous with respect to the paired-pulse plasticity of their SC inputs (Fig. $4 A$ ), as has previously been observed for unidentified SR interneurons (Sun et al., 2005). The majority of NPY + cells in SR have PPF of their SC inputs (9 of 16), while a subset of cells has PPD (7 of 16). We therefore divided the NPY + Ivy cells into two groups, called Ivy-PPF cells and Ivy-PPD cells. There were differences in the kinetics of SC EPSCs onto Ivy-PPF and Ivy-PPD cells, but no difference in input resistance or resting membrane potential of the cells (Table 1).

Variability has previously been seen in the short-term plasticity of TA inputs to neurogliaform cells during constantfrequency stimulation (Price et al., 2005); however, these synapses show exclusively short-term facilitation in response to physiologically derived stimulation (Fig. 4B). In contrast, SC synapses onto Ivy cells again have two patterns of responses to the PST, with Ivy-PPF and Ivy-PPD interneurons (Fig. 4C,D) showing short-term facilitation and depression, respectively. The overall amount of facilitation was greater for Ivy-PPF cells compared with neurogliaform cells, and both were different from Ivy-PPD cells (Fig. 4E). Plotting average normalized responses versus instantaneous frequency (reciprocal of interstimulus interval) shows that the frequency dependence of short-term plasticity is also distinctive among the three groups (Fig. 4F). Although there was no difference in paired-pulse facilitation, re- 
A

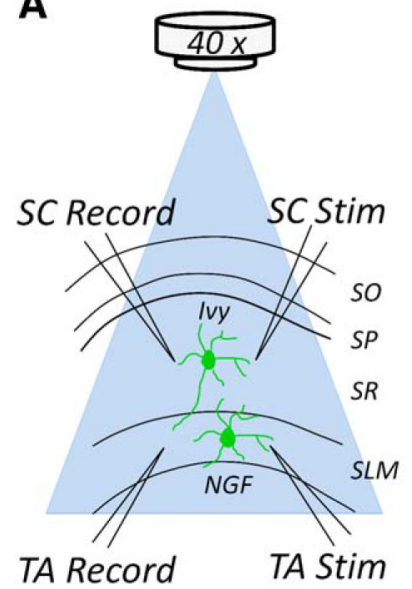

B

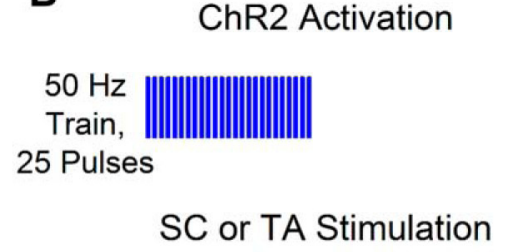

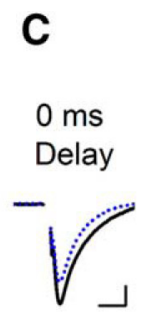

$\begin{array}{ll}0 \mathrm{~ms} & \\ \text { Delay } & \end{array}$

$500 \mathrm{~ms}$

Delay

D

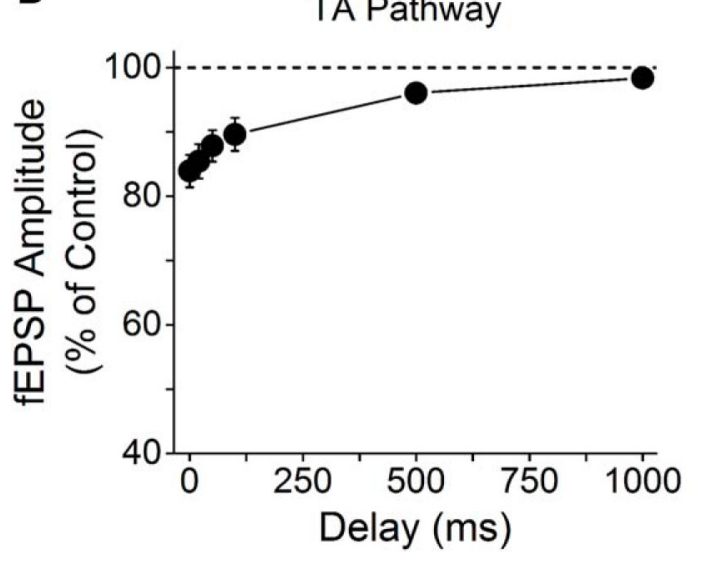

E

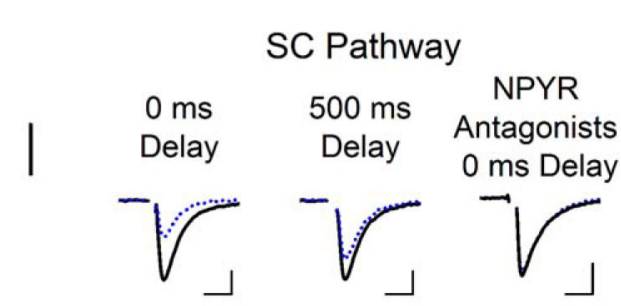

TA Pathway

$500 \mathrm{~ms}$ NPYR

Delay Antagonists
$0 \mathrm{~ms}$ Delay

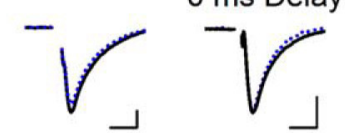

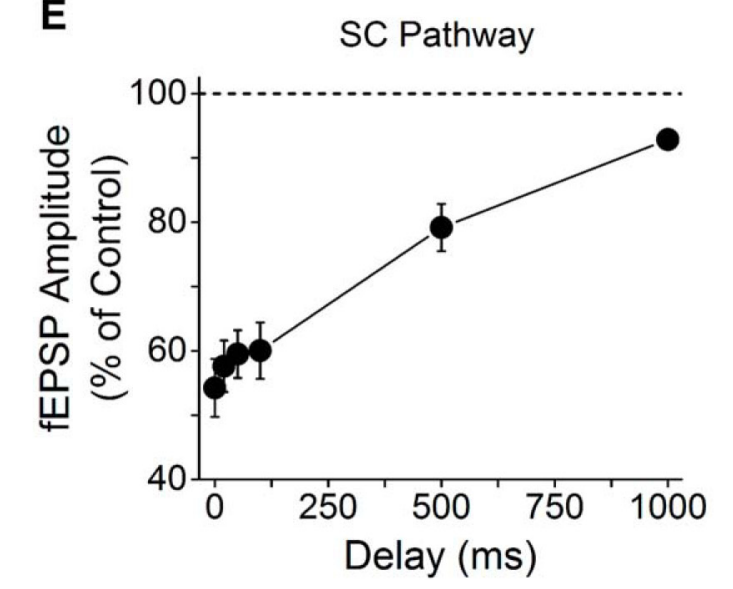

Figure 3. Photostimulation of NPY + interneurons induces NPY release that modulates both SC and TA synapses. $A$, NPY-cre mice were crossed with ChR2 ${ }^{\text {fl/fl }}$ mice to drive ChR2 expression only in NPY + cells. A schematic diagram showing the experimental setup. Photostimulation of NPY + cells expressing ChR2 was applied by pulses of $470 \mathrm{~nm}$ blue light flashed over the CA1 region of the slice, and fEPSPs were recorded from TA or SC synapses in response to low-frequency electrical stimulation. $\boldsymbol{B}$, Photostimulation was applied as trains of 25 pulses at $50 \mathrm{~Hz}$ using a 6 ms pulse width. For either the SC or TA pathway, a single electrical pulse was delivered at $0.03 \mathrm{~Hz}$, applied with variable delay $(0-1000 \mathrm{~ms})$ after the end of the photostimulation train. $C$, Example traces of the reduction caused by NPY release on the fEPSP at 0 or $500 \mathrm{~ms}$ after the $50 \mathrm{~Hz}$ train. The top shows fEPSPs from stimulating the TA pathway, and the bottom shows fEPSPs from the SC pathway. The black line represents average traces from the interleave controls (no ChR2 activation), and the dotted blue line represents average traces with ChR2 activation. Blocking the NPY Y1 and Y2 receptors (5 $\mu \mathrm{m}$ BIBP3226 and $5 \mu \mathrm{m}$ BIIE0246) blocks the effect of ChR2 activation in both pathways. Calibration: $0.25 \mathrm{mV}, 10 \mathrm{~ms}$. D, Group data showing the effects of ChR2-induced NPY release on the TA pathway at various intervals (one-way ANOVA, $F_{(5,36)}=7.32, p<0.05 ; n=7$ ). $\boldsymbol{E}$, Group data showing the effects of ChR2-induced NPY release on the $S C$ pathway at various intervals (one-way ANOVA, $\left.F_{(5,30)}=16.79, p<0.05 ; n=6\right)$. Recording, Record; Stim, stimulation.

sponses to the PST reveal that there are differences in short-term plasticity of inputs to neurogliaform and Ivy-PPF cells in response to temporally complex stimulation.

\section{Spiking of hippocampal NPY interneurons also expresses heterogeneity}

We next tested whether these differences in short-term plasticity cause similar differences in synaptically evoked spiking of the three NPY + cell types. PST stimulation of TA inputs onto neurogliaform cells induced robust short-term facilitation of spike probability (measured with cell-attached recording; Fig. 5A). PST stimulation of SC inputs caused facilitation of spike probability in Ivy-PPF cells (Fig. 5B), but short-term depression in Ivy-PPD cells (Fig. 5C), corresponding with the short-term plasticity of their inputs. The amount of facilitation increases with frequency for both neurogliaform and Ivy-PPF cells (Fig. 5D), which will facilitate NPY release. In contrast, Ivy-PPD cells have short-term depression of their spiking across a wide range of stimulus frequencies (Fig. 5D). This means that higher frequencies will re- cruit Ivy-PPF and neurogliaform cells to fire more while causing Ivy-PPD cells to fire less.

While it is well known that interneurons are highly heterogeneous with respect to their intrinsic firing properties (Tricoire et al., 2011), it is not known whether this correlates with differences in the short-term plasticity of their synaptic inputs. We next compared the intrinsic firing of neurogliaform and Ivy cells and found that neurogliaform cells are the most excitable, having a higher initial firing frequency and more spikes per current step, while Ivy-PPD cells are less excitable (Fig. $5 E-G$ ). Surprisingly, Ivy-PPF cells are the least excitable (Fig. $5 E-G$ ). Neurogliaform and Ivy cells have been shown to have a phenomenon called persistent firing, where spontaneous action potentials continue after stimulation ends (Sheffield et al., 2011; Armstrong et al., 2012). We observed persistent firing in the majority $(86 \%)$ of neurogliaform cells tested, but in only a small fraction of Ivy cells (25\%). The differences in short-term plasticity of the synaptic inputs, together with differences in their intrinsic firing properties, likely contribute to the distinct pat- 
A
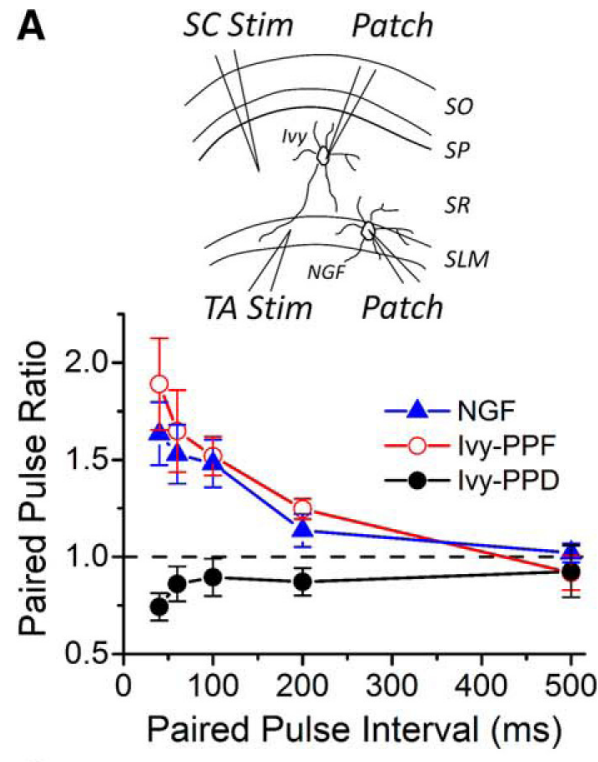

C

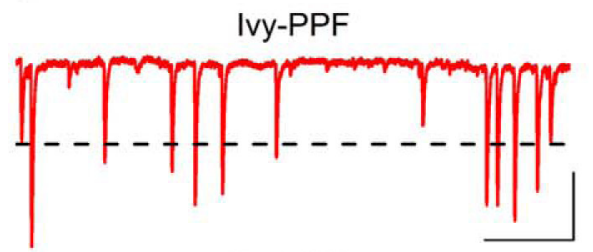

Ivy-PPD
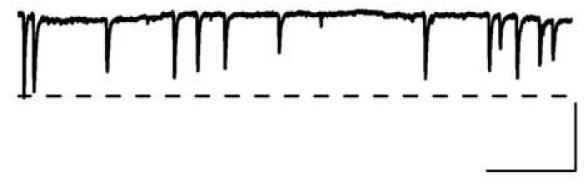

E

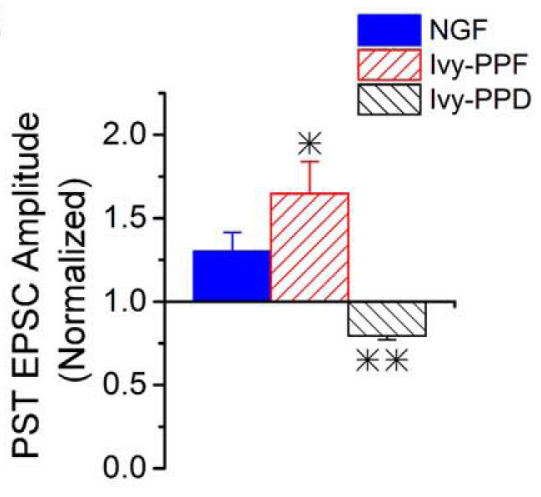

B

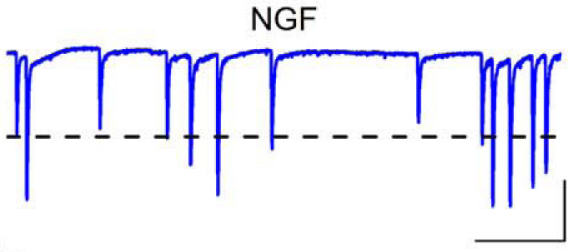

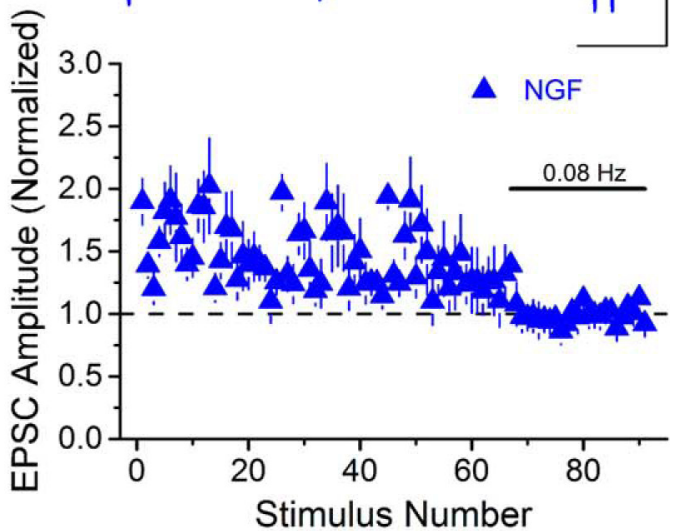

D
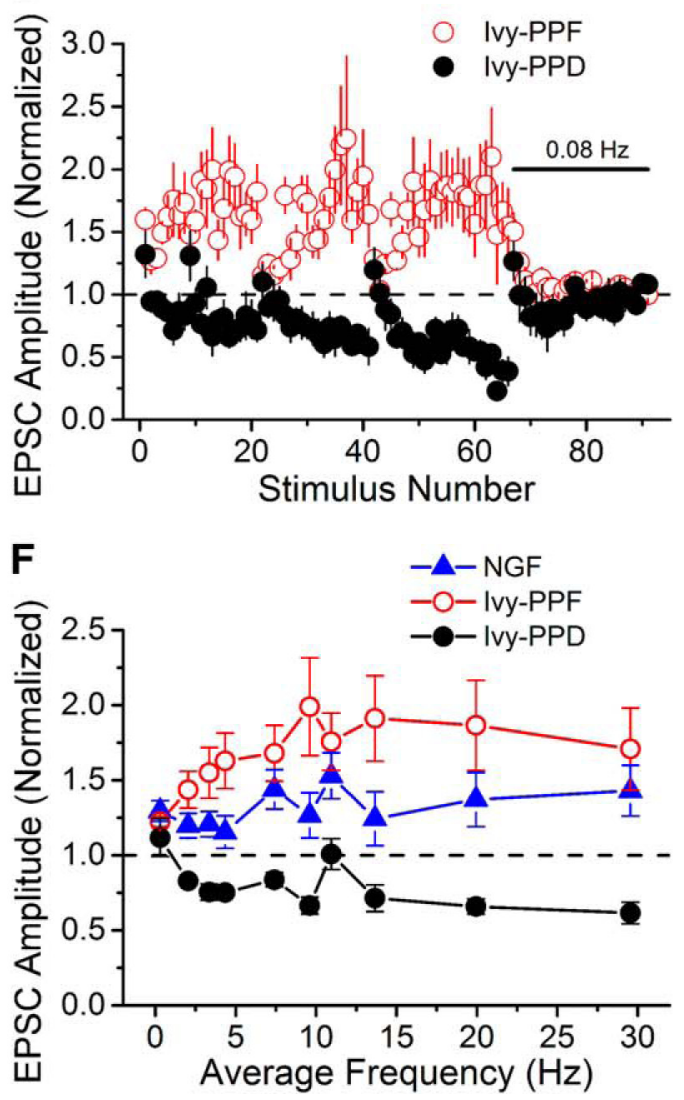

Figure 4. Short-term plasticity of excitatory inputs to NPY + interneurons in hippocampal CA1 area shows cell specificity. $A$, Top, A schematic diagram showing patch-clamp (Patch) recording from hippocampal SR Ivy or SLM neurogliaform cells following SC or TA stimulation (Stim), respectively. Bottom, Group data of the paired-pulse ratio of excitatory inputs onto Ivy cells or neurogliaform cells in response to either SC or TA stimulation. While SC synapses onto the majority of Ivy cells show paired-pulse facilitation (Ivy-PPF, $n=9$ ), a subset of Ivy cells expressed paired-pulse depression instead (Ivy-PPD, $n=7$ ). However, the TA excitatory inputs onto neurogliaform interneurons in SLM only expressed paired-pulse facilitation ( $n=6$ ). Paired-pulse ratios of Ivy-PPD cells are different from both neurogliaform and Ivy-PPF cells; however, neurogliaform and lvy-PPF cells are not different from each other (tw0-way ANOVA, $\left.F_{(2,82)}=19.78, p<0.05\right)$. $B$, Group data show that PST stimulation of TA inputs onto neurogliaform cells causes short-term facilitation $(n=9)$. Inset, Example EPSC trace from $2.5 \mathrm{~s}$ during the application of the PST pattern to TA synapses onto a neurogliaform cell. Calibration: 200 pA, 400 ms. C, A 2.5 s recording of EPSCs in response to stimulation of the SC pathway onto Ivy-PPF and Ivy-PPD cells, respectively, during the PST pattern. Calibration: 100 pA, 400 ms. D, Stimulation of the SC pathway with the PST drives different types of short-term plasticity onto NPY + cells in stratum radiatum (tw0-way ANOVA, $F_{(1,648)}=542.51, p<0.05 ; n=7 / 5$, respectively). $E$, Averaged EPSC amplitude during PST burst pattern showed a significant difference among neurogilaform, Ivy-PPF, and Ivy-PPD NPY + cells (one-way ANOVA, $F_{(2,18)}=8.63, p<0.05 ; n=9 / 7 / 5$, respectively). ${ }^{*} p<0.05$, comparing neurogliaform and lvy-PPF; ${ }^{* *} p<0.05$, Ivy-PPD cells are significantly different from both Ivy-PPF and neurogliaform cells. $\boldsymbol{F}$, Excitatory inputs to the three NPY + cell types respond differently across the range of frequencies applied during the PST pattern (two-way ANOVA, $F_{(2,170)}=47.76, p<$ 0.05), indicating cell-type specificity to the frequency dependence of short-term plasticity. 
Table 1. NPY + Ivy-PPF and Ivy-PPD cells have differences in SC EPSC kinetics, but not in cell electrophysiological responses

\begin{tabular}{lcc}
\hline & $\operatorname{Ivy}-\operatorname{PPF}(n=14)$ & $\operatorname{Ivy}-\operatorname{PPD}(n=8)$ \\
\hline EPSC properties & & \\
$\quad$ Latency (ms) & $2.81 \pm 0.22$ & $3.97 \pm 0.53^{*}$ \\
$\quad$ Half-width (ms) & $8.46 \pm 1.17$ & $4.93 \pm 0.55^{*}$ \\
$\quad$ Rise time (ms) & $1.74 \pm 0.27$ & $0.96 \pm 0.09^{*}$ \\
$\quad$ Decay $(\tau$ in ms) & $7.80 \pm 0.87$ & $4.94 \pm 0.56^{*}$ \\
Cell electrophysiological responses & & \\
$\quad$ Input resistance $(\mathrm{M} \Omega)$ & $411.2 \pm 48.5$ & $308.4 \pm 35.8$ \\
$\quad$ Resting potential $(\mathrm{mV})$ & $-56.6 \pm 1.5$ & $-58.6 \pm 1.3$ \\
\hline
\end{tabular}

Values are reported as the mean \pm SEM. The number in the parenthesis indicates the number of cells. SC-induced EPSCs have differences in their kinetics that correlate to the classification of SR NPY + cells as lvy-PPF and lvy-PPD cells. Basic cellular properties are not different between the cell types. However, there was a trend that the lvy-PPF cells had a higher input resistance than Ivy-PPD cells $(p=0.11)$.

${ }^{*} p<0.05$, Student's $t$ test; significantly different from Ivy-PPF NPY + cells.

terns of synaptically evoked spiking during PSTs that are observed in Figure 5A-C. In addition, the lower intrinsic excitability of Ivy cells will make them less likely to be recruited to fire and release NPY with SC stimulation, potentially explaining the pathway specificity of NPY release.

\section{Ivy interneurons in SR also receive facilitating input from TA synapses}

Many interneurons in SR receive input from TA as well as SC (Klausberger and Somogyi, 2008). Consistent with this, NPY cells near the border of stratum lacunosum-moleculare and stratum radiatum can integrate TA and SC inputs to drive spiking (Milstein et al., 2015). Additionally, Ivy cells have been shown to have a small percentage of their dendrites in SLM (Somogyi et al., 2012), although the properties of TA inputs onto SR Ivy cells have not been well described. To determine whether there are differences in the short-term plasticity of the TA inputs to Ivy-PPF and Ivy-PPD cells, we compared short-term plasticity of TA and SC inputs onto the same Ivy interneuron using two-pathway alternating stimulation (Fig. 6A). Surprisingly, both Ivy-PPF and IvyPPD cells express only the PPF of their TA inputs (Fig. 6B, C). This indicates that the short-term plasticity of synapses onto $\mathrm{NPY}+$ interneurons can be pathway specific. As a result, the relative strength of TA versus SC inputs onto Ivy interneurons will vary depending upon input frequency. PST stimulation of TA synapses also caused robust facilitation of synaptically evoked spiking in all Ivy cells (Fig. $6 D, E$ ). Therefore, TA inputs may be important to drive spiking of Ivy cells and to enable NPY release.

\section{Combined TA and SC stimulation drives endogenous NPY release that modulates SC synapses onto pyramidal cells} We next tested whether combined TA and SC stimulation can drive NPY release that modulates SC synapses onto pyramidal cells. PST stimulation was applied to the TA pathway $20 \mathrm{~ms}$ before delivery of the SC input (Fig. 7A), simulating the delay in the trisynaptic circuit (Remondes and Schuman, 2002), and the effects on SC fEPSPs were tested. fEPSPs recorded in response to SC stimulation with the PST now show a significant increase in short-term facilitation when NPYRs are blocked (Fig. $7 B, C$ ), demonstrating effects of endogenously released NPY on SC synapses. This indicates that the integration of TA and SC stimulation is necessary to cause NPY release from NPY + cells in SR.

Alternatively, the NPY that modulates SC synapses in response to combined TA and SC stimulation (and also photostimulation) could potentially be released by neurogliaform cells in SLM. Although neurogliaform cell axons and dendrites are mainly restricted to SLM (Price et al., 2005), they have a particularly high density of presynaptic boutons, enabling volume transmission of GABA release (Overstreet-Wadiche and McBain, 2015). Therefore, NPY released by neurogliaform cells could potentially spill over to SR to inhibit SC synapses. To see whether the modulation of SC synapses by endogenously released NPY occurs with PST stimulation of TA synapses alone, we recorded fEPSPs from both TA and SC pathways, while stimulating TA with a PST and SC with a slow constant-frequency train $(0.1 \mathrm{~Hz}$; Fig. $7 D)$. The release of endogenous NPY was observed in the TA recordings, which received PST input (Fig. $7 E, F$ ); however, the lowfrequency SC responses were not affected by NPYR antagonists even during the time that PST stimulation was applied to TA (Fig. $7 G$ ). These data show that NPY released from neurogliaform cells upon TA stimulation is not able to diffuse from SLM to regulate SC synapses. In addition, these results show that TA stimulation alone is not sufficient to trigger NPY release from Ivy cells, potentially because of their lower excitability. Together, these experiments demonstrate that combined SC and TA stimulation is needed for triggering NPY release from NPY + Ivy cells in SR.

NPY released by PST stimulation has a similar effect of reducing short-term plasticity at both SC and TA synapses. However, the release of NPY onto SC synapses requires the integration of the two input pathways; in contrast, the modulation by NPY of TA synapses is pathway autonomous. This pathway specificity in triggering NPY release suggests that NPY may play a larger role in modulating TA synapses, which have been shown to be particularly vulnerable to stress (Kallarackal et al., 2013).

\section{Predator scent stress causes increased anxiety and reduced release of endogenous NPY}

NPY levels are reduced in patients with PTSD (Reichmann and Holzer, 2016); however, it is unknown how NPY release is affected. In rodents, exposure to predator odors elicits fear responses, leading to long-lasting anxiety that mimics aspects of PTSD (Neumann et al., 2011). Predator scent stress also causes a reduction in NPY (Cohen et al., 2012), and the severity of anxiety symptoms correlates with the extent of NPY reduction in hippocampus (Cohen et al., 2012), although the effects on hippocampal function have not yet been shown. To address this, we asked whether predator scent stress alters the release of endogenous NPY in response to physiologically derived stimulation, and tested for effects on TA synapses.

Young adult mice were given two exposures to TMT, a volatile compound isolated from fox feces that provokes fear in rodents (Rosen et al., 2015), followed $7 \mathrm{~d}$ later by behavioral testing for anxiety (Fig. 8A). TMT-exposed mice spent significantly less time in the open arms of the elevated plus maze (Fig. $8 B$ ) and had fewer open arm entries (data not shown), causing an increased anxiety index level (Cohen et al., 2012; Fig. 8C). Additionally, plasma NPY levels were significantly decreased in TMT-exposed mice (Fig. 8D). Together, these data show that predator scent stress causes enhanced anxiety and reductions in NPY.

We next tested for the effects of stress-induced anxiety on NPY release in the TA pathway. In slices from vehicle-treated mice, NPY was released in response to TA stimulation with the PST (Fig. $8 E$ ), as previously shown (Fig. 2A). In contrast, there was no effect of the NPYR antagonists on synaptic responses in slices from TMT-exposed mice (Fig. $8 F$ ). This indicates that there is a reduction in the release of NPY, the responsiveness of the receptors to NPY, or both. However, there was no change in NPYR sensitivity to bath-applied NPY between the two groups (Fig. 8G). Therefore, these data demonstrate that pred- 

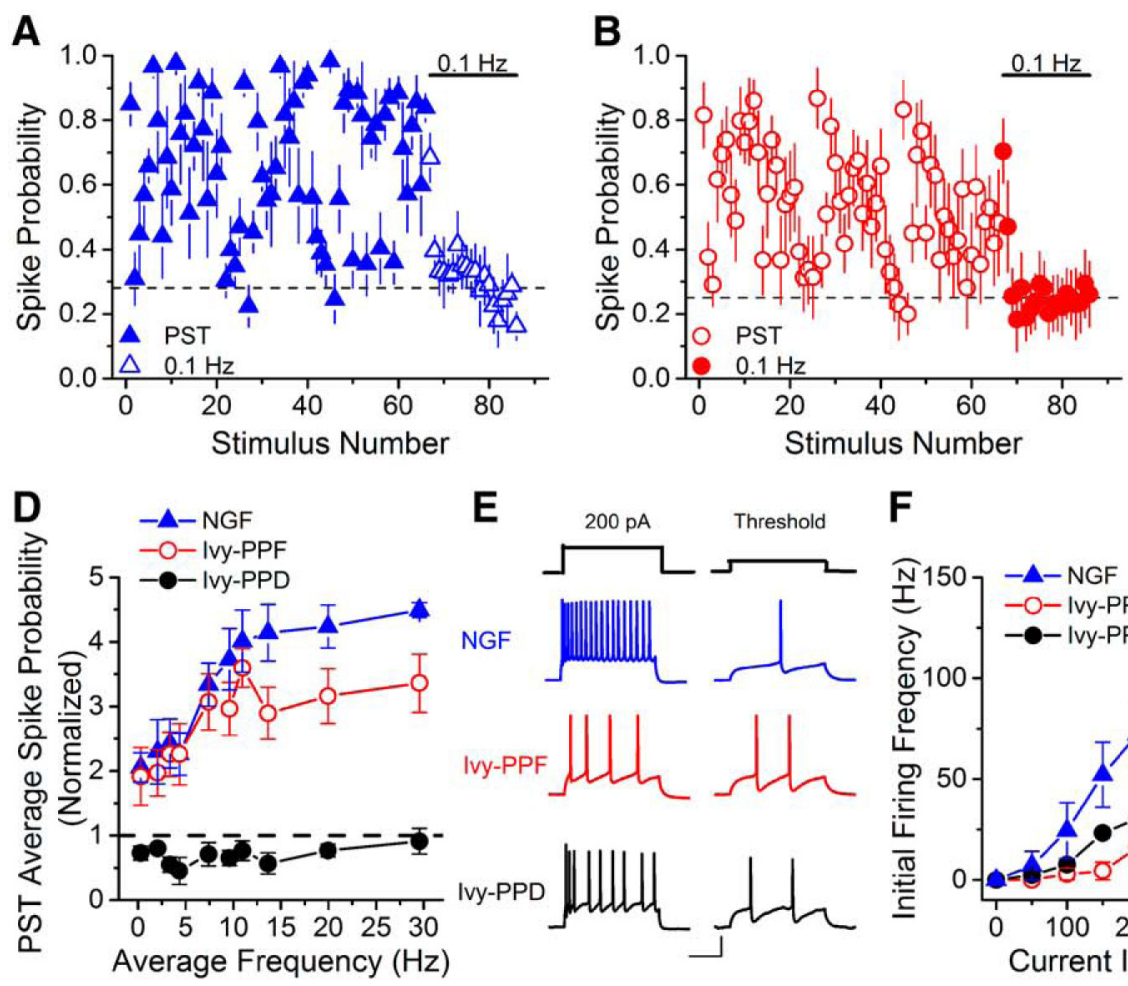

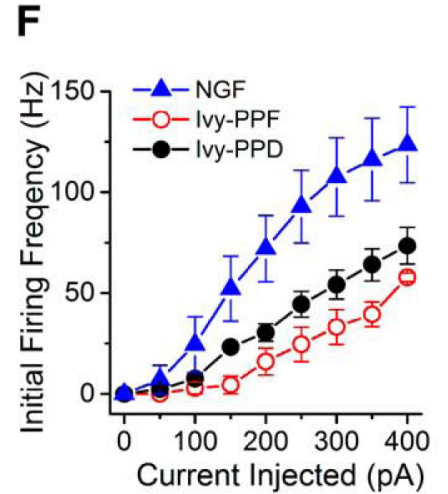

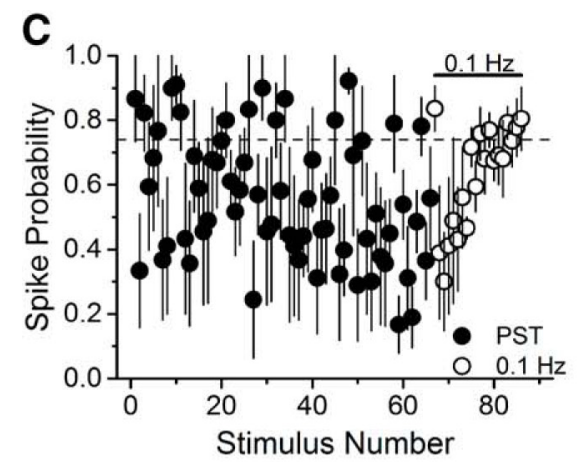

G

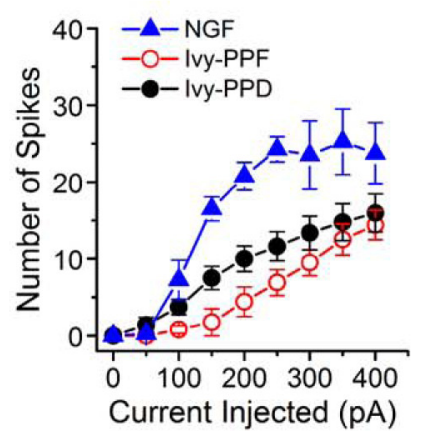

Figure 5. Spiking properties of hippocampal CA1 NPY + interneurons are different. $\boldsymbol{A}-\boldsymbol{C}$, Group data from synaptically evoked spiking of neurogliaform cells $(\boldsymbol{A})$, Ivy-PPF (B), and Ivy-PPD ( $)$ following TA or SC stimulation with a PST ( $n=6 / 7 / 3$, respectively) show that the cells have different spiking patterns. The spike probability during the control period was set differently for the various cell types to show the short-term plasticity of their responses. The neurogliaform cells and Ivy-PPF cells had a spike probability of $\sim 0.25-0.3$, whereas the Ivy-PPD cells had a spike probability set to $\sim 0.8$. D. The spike probability vs frequency graph demonstrates that even though the neurogliaform and lvy-PPF cells are similar at lower frequencies, at higher frequencies the Ivy-PPF cells have less spiking (two-way ANOVA, $F_{(2,130)}=79.72, p<0.05$ ). The Ivy-PPD cells have extremely reduced spiking compared with the other NPY + cell types. Spike probability is normalized to the spike probability that occurs during the $0.1 \mathrm{~Hz}$ control period. $\boldsymbol{E}$, Left, Example traces of intrinsic firing for NPY + cells held at $-60 \mathrm{mV}$ in response to a $200 \mathrm{pA}$ current step. Right, Example traces depicting the characteristic delayed spiking of NPY + cells at threshold (Tricoire et al., 2010). Calibration: $25 \mathrm{mV}, 200 \mathrm{~ms}$. $\boldsymbol{F}$, Initial firing frequency vs injected current is different among Ivy-PPF, Ivy-PPD, and neurogliaform cells (two-way ANOVA, $F_{(20,109)}=1.98, p<0.05 ; n=5 / 5 / 4$, respectively). The neurogliaform cells are more excitable than either the Ivy-PPF or Ivy-PPD cells. Surprisingly, the least excitable cell type is the Ivy-PPF cell. $G$, Total number of spikes generated by each current step is different among the three groups (two-way ANOVA, $F_{(20,107)}=$ $7.11, p<0.05 ; n=5 / 5 / 4$, respectively).

ator scent stress abolishes NPY release. Interestingly, shortterm facilitation is significantly enhanced at TA synapses onto CA1 pyramidal cells in slices from TMT-exposed mice compared with vehicle mice (Fig. $8 H-J$ ). The difference is caused by NPY, because it is no longer seen when NPYRs are blocked (Fig. 8J). Together, this demonstrates that predator scent stress impairs endogenous NPY release and causes TA synapses to function abnormally.

\section{Discussion}

In summary, we discovered that endogenously released NPY reduces the short-term plasticity of TA synapses onto pyramidal cells during stimulation with a physiologically based spike pattern. In contrast, the release of NPY that regulates SC synapses requires the activation of both SC and TA pathways. This pathway specificity of NPY release results from differences in synaptically evoked firing of three functionally distinct subgroups of $\mathrm{NPY}+$ interneurons in CA1. Importantly, we find that predator scent stress impairs the release of endogenous NPY in the TA pathway, thereby altering the dynamics of TA synapses. The loss of NPY release, therefore, contributes to CA1 circuit dysfunction in response to stress.

An advantage of the predator scent stress model, which has been proposed to be a more naturalistic model of traumainduced anxiety, is that it involves nonpainful stressors (Neumann et al., 2011). Our data are the first to demonstrate that predator scent stress impairs NPY release and increases hippocampal short-term facilitation. Enhancing short-term plasticity of TA synapses will boost the relative strength of this pathway to drive CA1 cell spiking, thus altering the output of hippocampus (Remondes and Schuman, 2002). Because this pathway is important for fear learning (Lovett-Barron et al., 2014) and memory consolidation (Remondes and Schuman, 2004), greater TA facilitation could increase the consolidation of fear learning, as seen in other PTSD models (Yamamoto et al., 2009). Future studies may reveal whether other models of stress-induced anxiety/PTSD, such as single prolonged stress (Serova et al., 2013) or chronic unpredictable stress (Kallarackal et al., 2013), cause similar impairment of hippocampal NPY release and alterations in TA synaptic dynamics.

Enhancement of NPY has been proposed as a therapy for anxiety/PTSD, and intranasal infusion of NPY alleviates anxiety after single prolonged stress (Serova et al., 2013). In addition, environmental enrichment and exercise, both of which reduce anxiety in response to predator exposure, have been shown to upregulate NPY (Hoffman et al., 2015; Ragu Varman and Rajan, 2015) and Y1 receptors (Ragu Varman and Rajan, 2015). It remains to be determined whether these potential therapeutic measures cause enhanced NPY release in hippocampus, and what role that plays in anxiety symptoms. Interestingly, the anxiolytic effects of environmental enrichment are lost in NPY-null mice (Reichmann et 

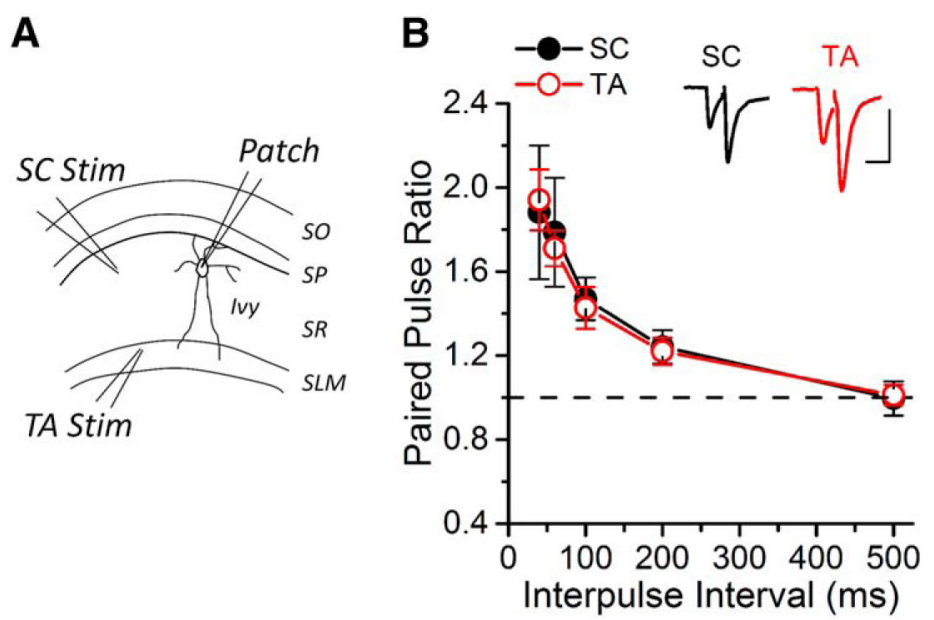

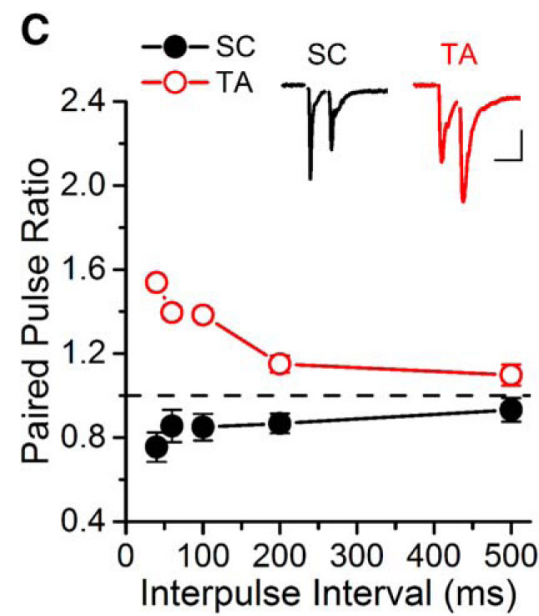

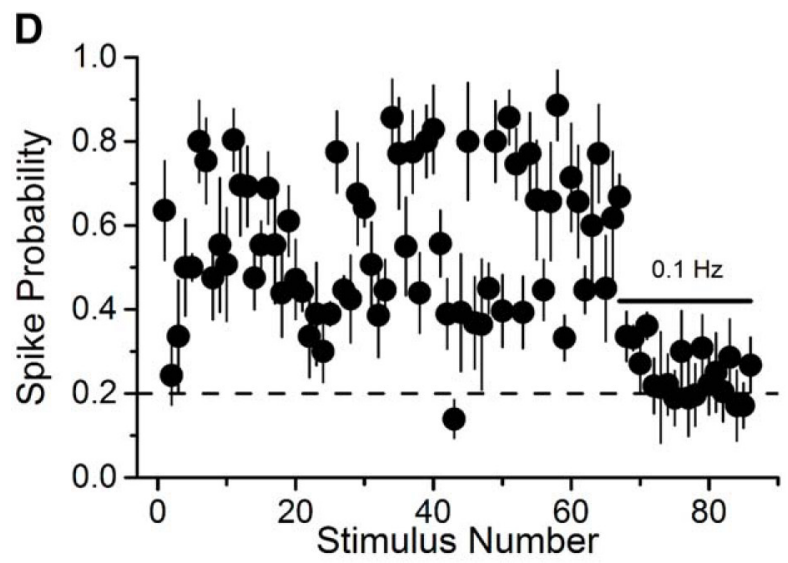

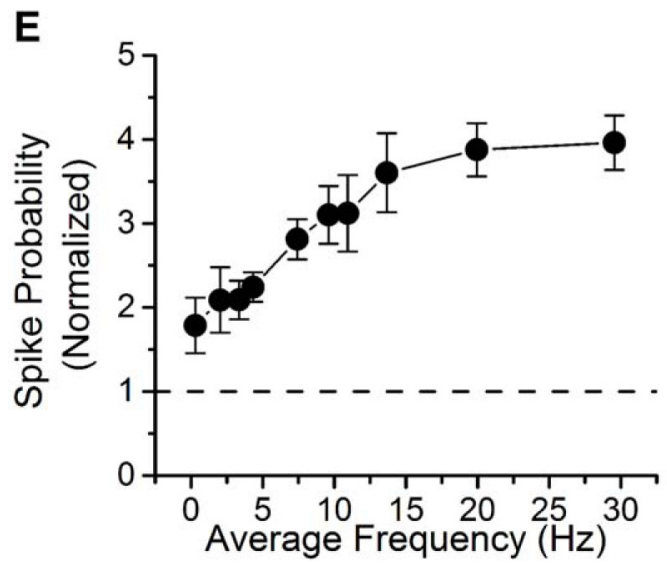

Figure 6. TA inputs to lvy cells in SR facilitate. A, A schematic diagram showing patch-clamp (Patch) recording from an SR Ivy cell during alternating SC or TA stimulation (Stim) onto the same $\mathrm{NPY}+$ cell. $\boldsymbol{B}$, lvy-PPF cells have similar PPF for both SC and TA inputs (two-way ANOVA, $F_{(4,38)}=0.83, p=0.83 ; n=5$ ). Insets, Example EPSC traces for a $40 \mathrm{~ms}$ interval for both pathways onto the same Ivy-PPF cell. Calibration: 40 pA, 25 ms. C, Ivy-PPD cells have different paired-pulse plasticity at SC and TA synapses (two-way ANOVA, $F_{(4,20)}=23.32, p<0.05 ; n=3$ ). Insets, Example EPSC traces for a $40 \mathrm{~ms}$ interval for both pathways onto the same Ivy-PPD cell. Calibration: 50 pA, 25 ms. D, Synaptically evoked spiking of Ivy cells shows short-term facilitation in response to PST stimulation of TA synapses $(n=5)$ due only to receiving synaptic facilitation of their TA inputs. $\boldsymbol{E}$, The TA pathway drives the lvy cells to reliably fire at high frequencies. The spike probability is normalized to spike probability during $0.1 \mathrm{~Hz}$ constant frequency applied at the end of the PST.

al., 2016), suggesting a critical role for NPY. NPY is also regulated by estradiol, which enhances NPY release in hippocampus (Ledoux et al., 2009) and causes faster extinction of contextual fear conditioning (Chang et al., 2009; Stockhorst and Antov, 2015). However, the infusion of NPY into infralimbic cortex impairs fear extinction memory (Vollmer et al., 2016), and viral overexpression of NPY in cells that do not normally express it causes learning impairment (Sørensen et al., 2008). Because increasing NPY levels throughout the brain could potentially have detrimental effects, it is important to discover which pathways are involved in the anxiolytic effects of NPY, and to find ways to specifically increase NPY release from those pathways.

Spontaneous release of endogenous NPY has previously been shown to modulate mossy fiber synapses in CA3 in an animal model of temporal lobe epilepsy (Tu et al., 2005). However, our study is the first demonstration of the impact of endogenously released NPY on SC and TA short-term plasticity in response to stimulation with a physiologically derived spike train. While no in vitro experiment completely duplicates in vivo conditions, these experiments bring us one step closer to the physiological situation and advance our understanding of how temporally complex activity regulates NPY release from NPY + interneurons. NPY released during PST stimulation reduces glutamate release from synapses onto pyramidal cells; as a result, blocking
NPYRs increases short-term facilitation. This is different from the effects of exogenous NPY, where the increased amount of paired-pulse facilitation caused by bath-applied NPY is secondary to the reduction in initial release probability (Colmers et al., 1987, 1988; Qian et al., 1997). Surprisingly, the effects of NPY release are seen throughout the PST, which challenges the longheld assumptions that neuropeptide release in hippocampus requires long high-frequency trains (van den Pol, 2012) and occurs primarily under pathological conditions, such as epilepsy (Tu et al., 2005; Kovac and Walker, 2013). This novel, physiologically based assay can detect the effects of endogenously released NPY with temporal resolution and pathway specificity. Because NPY has been implicated in many neurological and neuropsychiatric disorders (Colmers and El Bahh, 2003; Heilig, 2004; Eaton et al., 2007; Sørensen et al., 2009; Decressac and Barker, 2012; Reichmann and Holzer, 2016), including epilepsy, depression, and schizophrenia, this technique could be widely used to test for physiologically relevant changes and the pathway specificity of NPY release in various disease models.

Diversity of NPY + cells has been seen in several brain regions, including hippocampus (Tricoire et al., 2010), cortex (Karagiannis et al., 2009), and striatum (Ibáñez-Sandoval et al., 2011). Our data reveal three functionally distinct subtypes of NPY + cells in SR and SLM of hippocampal CA1, based on differences in 
A
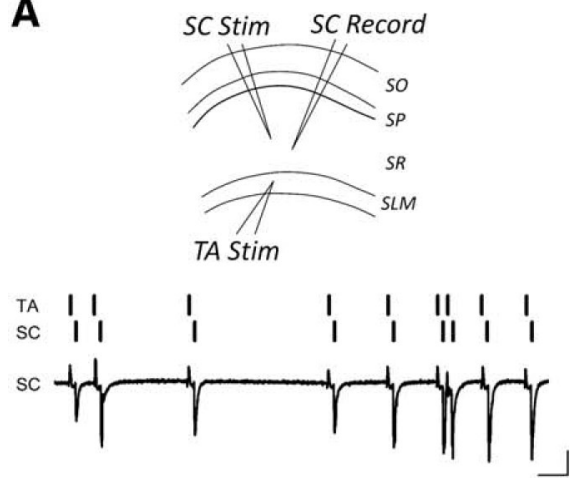

D
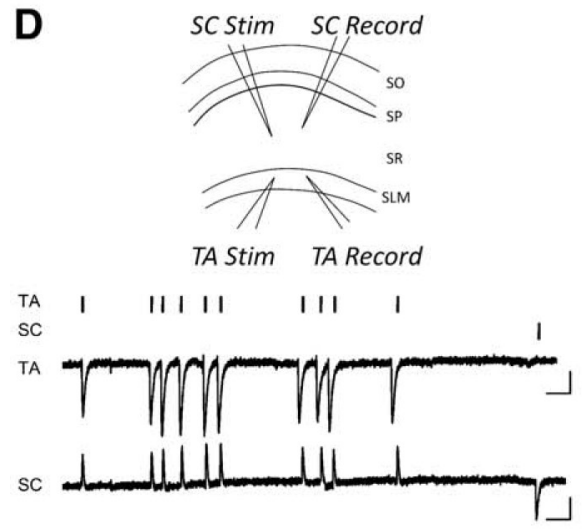

B

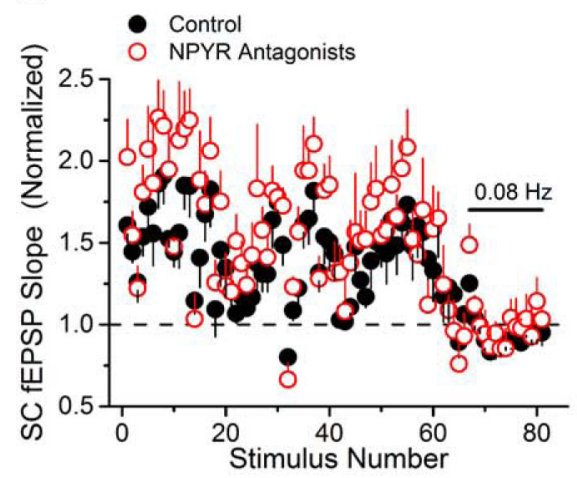

E

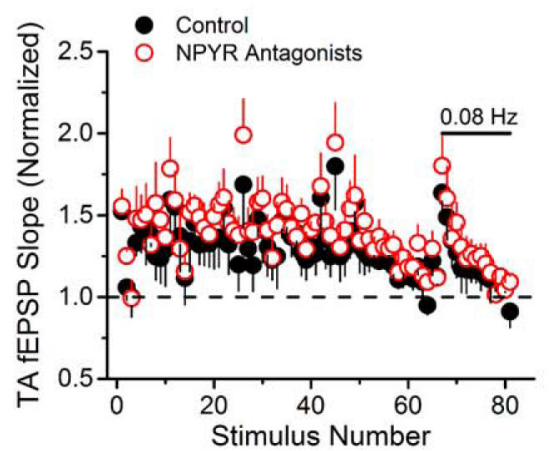

C

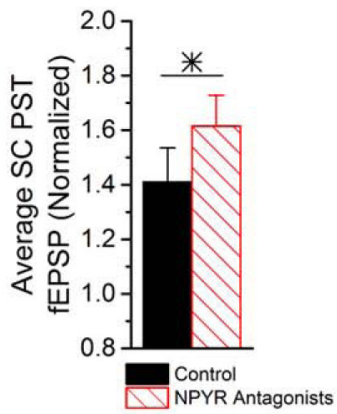

F

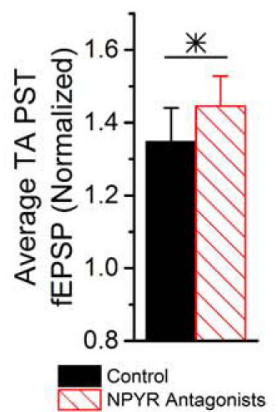

G

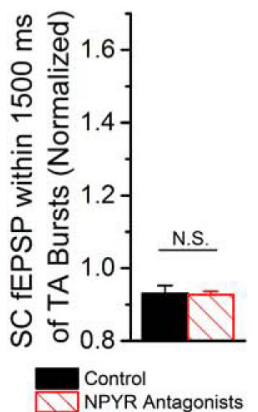

Figure 7. Combined TA and SC stimulation (Stim) drives NPY release that modulates SC synapses. A, Top, A schematic diagram showing fEPSP recordings (Record) from SR following combined TA and SC stimulation with the PST. TA pathway PST stimulation is applied 20 ms before SC stimulation. Bottom, Stimulus pattern and example trace of fEPSP recorded in SR with combined TA and SC stimulation. Calibration: $0.4 \mathrm{mV}, 100 \mathrm{~ms}$. B, Group data show that combined stimulation of the TA and SC pathways causes the release of NPY that reduces short-term facilitation of SC synapses onto CA1 pyramidal cells, which is seen by the increased facilitation of SC fEPSPs when NPYRs are blocked by Y1 and Y 2 receptor antagonists (two-way ANOVA, $F_{(1,528)}=20.18, p<0.05 ; n=5$ ). C, The average of the normalized SC fEPSP slopes shows a significant increase during the PST when NPYRs were blocked (paired $t$ test, $p<0.05 ; n=4)$. D, Top, Schematic showing the placement of stimulation and recording electrodes. PST stimulation was applied to the TA pathway, while a low-frequency (0.1 Hz) constant stimulation was applied to the SC pathway, and both TA and SC fEPSPs were recorded. Bottom, Stimulus timing and example traces of TA and SC fEPSPs. Calibration: $0.2 \mathrm{mV}, 100 \mathrm{~ms}$. $\boldsymbol{E}$, Group data show that TA fEPSPs are facilitated in response to NPYR antagonists, indicating that NPY was released (tw0-way ANOVA, $F_{(1,396)}=26.32, p<0.05 ; n=4$ ). $\boldsymbol{F}$, There was significant change in the average of the normalized TA fEPSP slopes during the PST when NPYRs were blocked (paired t test, $p<0.05 ; n=4$ ). $G$, Average of SC fEPSP responses within 1.5 s of the end of TAPST bursts showed no effect of NPYR antagonists, indicating that $S C$ synapses are unaffected by NPY released by TA stimulation (paired $t$ test, $p=0.86 ; n=4$ ).

short-term plasticity, synaptically evoked spiking, and intrinsic excitability. We have referred to the NPY + cells in SLM as neurogliaform cells, and SR as Ivy cells, as previously classified in CA1 of the NPY-hrGFP mice (Tricoire et al., 2010). Our results would therefore indicate that there are two subtypes of Ivy cells in SR with functionally different properties. One of which, the IvyPPD cells, has never been reported, but likely corresponds to the subgroup of unidentified SR interneurons expressing PPD of their SC inputs (Sun et al., 2005). Alternatively, it is possible that one of the subtypes of SR NPY + cells is a previously undescribed $\mathrm{NPY}+$ cell that is distinct from Ivy cells. NPY has been shown to overlap with most interneuron molecular markers (Karagiannis et al., 2009), and it remains to be determined whether the two subtypes of NPY + cells in SR correlate with specific molecular markers. Ivy cells and the majority of neurogliaform cells in CA1 express neuronal nitric oxide synthase (nNOS) and derive from the medial ganglionic eminence, whereas a subset of neurogliaform cells from the caudal ganglionic eminence lacks nNOS (Tricoire et al., 2010). However, we did not see functionally distinct subtypes of neurogliaform cells, despite their potentially diverse origins. Although neurogliaform and Ivy cells have common origins and have previously been reported to have many similarities, this diversity in their synaptically evoked spiking is likely to be important for pathway and region specificity of NPY release.
We show that the modulation of TA synapses by NPY release is pathway autonomous. In contrast, our results show that the modulation of SC synapses by endogenously released NPY requires combined SC and TA stimulation. Consistent with this, NPY + cells near the border of SLM and SR can integrate TA and SC inputs to drive spiking (Milstein et al., 2015; Overstreet-Wadiche and McBain, 2015). Surprisingly, the effects of NPY released by PST stimulation were more robust in modulating TA synapses than SC synapses, even when combined stimulation was used. NPY + cells are more abundant in SR than SLM (Tricoire et al., 2010; Wierenga et al., 2010), and SC synapses are more sensitive than TA synapses to both exogenous NPY and optogenetically stimulated NPY release. PST stimulation must therefore cause greater spiking of neurogliaform cells than Ivy cells. Although both neurogliaform and Ivy-PPF cells have facilitating inputs, the higher intrinsic excitability of neurogliaform cells enables them to be more responsive to PST stimulation. The enhanced excitability of neurogliaform cells may also underlie their higher occurrence of persistent firing. Stimulation with PSTs has previously been shown to induce persistent firing in neurogliaform cells (Sheffield et al., 2011); however, the role of persistent firing in NPY release in response to PSTs has not been established. It also remains to be determined whether 
A

P28

TMT Exposure Repeat TMT Exposure
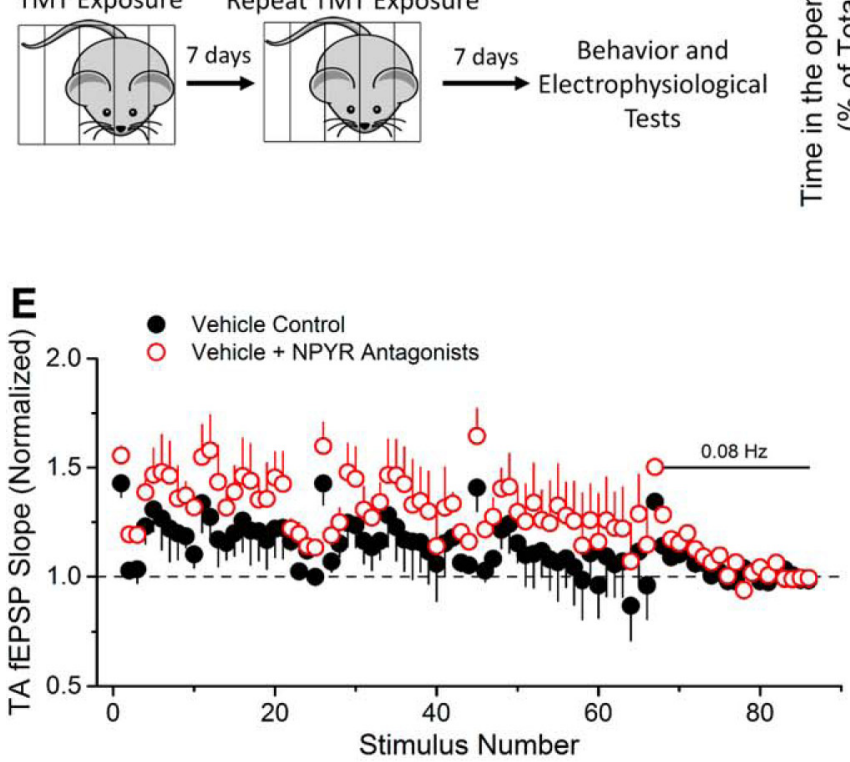

G

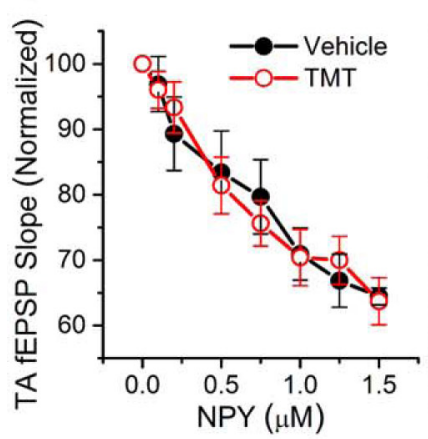

H

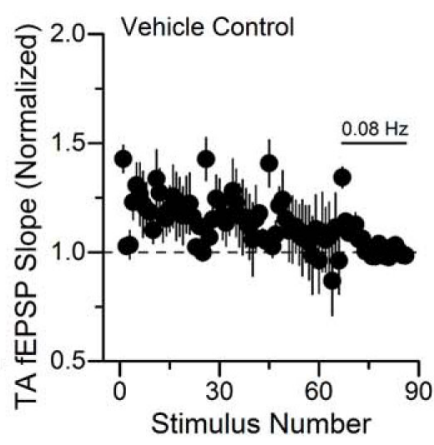

B

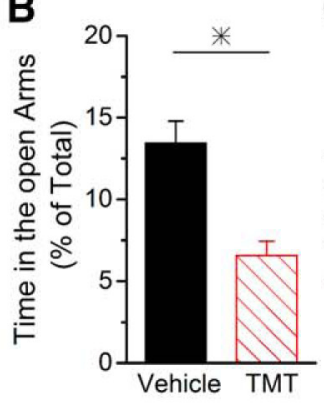

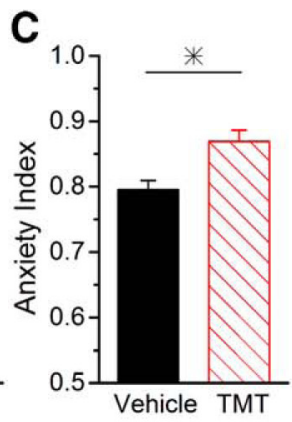

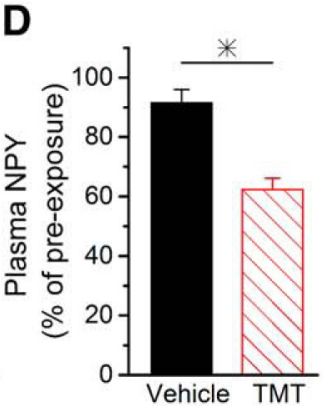

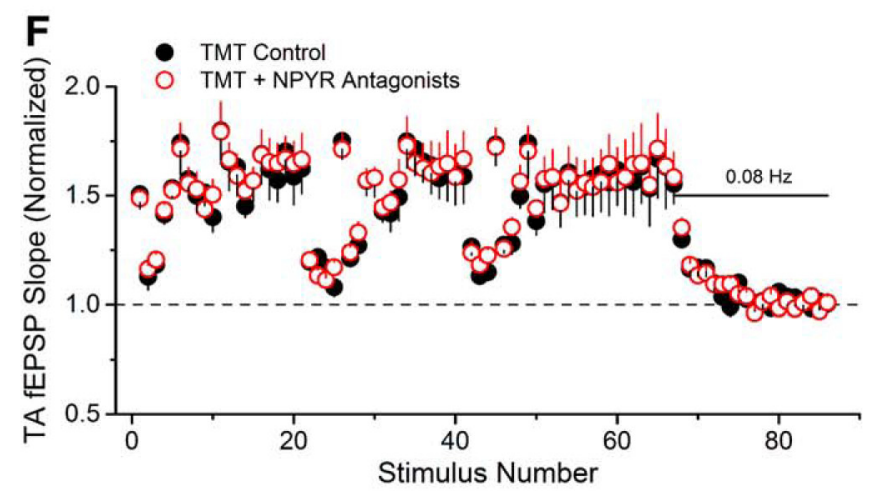
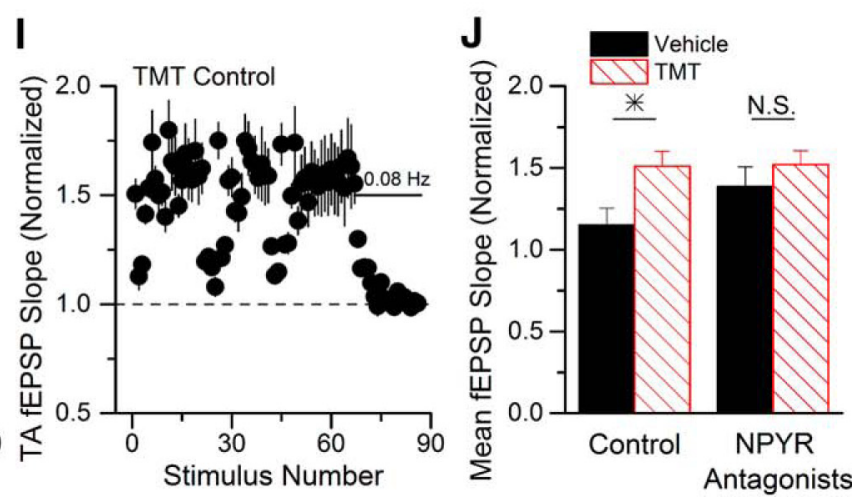

Figure 8. Predator scent stress (PSS) causes increased anxiety and impairs endogenous NPY release. $A$, A schematic depicting the time course of the experiment. PSS mice are exposed twice to TMT; the treatments are $7 \mathrm{~d}$ apart. Each exposure lasts for $20 \mathrm{~min}$. B, PSS mice show decreased time spent in the open arms of the elevated plus maze (Student's $t$ test, $p<0.05 ; n=20 / 22$, respectively), indicating enhanced anxiety. C, The enhanced anxiety is further reflected by the fact that PSS mice show an increase in the anxiety index (Cohen et al., 2012; Student's $t$ test, $p<0.05$; $n=20 / 22$, respectively). D, PSS causes a decrease in plasma NPY (Student's t test, $p<0.05 ; n=5 / 4$, respectively), normalized to NPY levels before exposure to TMT. Plasma NPY was only measured in a subset of the animals used for behavior. The anxiety behavior measured in these animals was not different from animals in which plasma NPY was not measured (two-way ANOVA, $F_{(1,41)}=1.87$, $p=0.18)$. $\boldsymbol{E}$, Group data show that NPY Y1 and Y2 antagonists increase the synaptic response size of TA synapses onto CA1 pyramidal cells during PST in slices from vehicle-exposed mice (two-way ANOVA, $\left.F_{(1,792)}=60.09, p<0.05 ; n=7\right) . F$, Group data show that NPY 1 and $Y 2$ antagonists do not change the synaptic response size of TA synapses onto CA1 pyramidal cells during PST in slices from PSS-exposed mice (two-way ANOVA, $F_{(1,660)}=0.35, p<0.05 ; n=6$ ). G, PSS does not alter the responsiveness of NPY receptors. The dose response of TA synapses onto CA1 pyramidal cells to bath-applied NPY is not altered in slices from PSS animals (two-way ANOVA, $F_{(7,54)}=0.48, p=0.85 ; n=5 / 4$, respectively). $\boldsymbol{H}, \boldsymbol{I}$, Short-term facilitation of TA fEPSPs is enhanced in animals exposed to TMT $(\boldsymbol{I}, n=7)$, compared with vehicle-treated animals $(\boldsymbol{H}, n=6)$. Data are replotted from $\boldsymbol{E}$ and $\boldsymbol{F}$. $\boldsymbol{J}$, The average normalized TA fEPSP in response to the PST is larger in slices from PSS mice compared with controls (Student's $t$ test, $p<0.05$ ). This difference in short-term plasticity is not seen when NPY Y1 and Y2 receptors are blocked, indicating that plasticity is caused by the reduced NPY release in PSS animals (Student's t test, $p=0.377$ ).

persistent firing can be induced in Ivy cells by PSTs, either in response to SC or combined SC and TA stimulation. Interestingly, the two types of Ivy cells are not different in the shortterm plasticity of their TA inputs. As a result, Ivy-PPD cells may release NPY preferentially in response to their TA inputs. In contrast, the Ivy-PPF cells are likely to be better at integrating their SC and TA inputs to drive NPY release.

Together, our results show that there are three functionally distinct types of NPY + cells that release NPY to regulate synaptic transmission and plasticity in the feedforward pathways of CA1. Differences in their intrinsic excitability and the short-term plasticity of their inputs confer pathway specificity to NPY release, suggesting that NPY plays a larger role in regulating the TA pathway than the SC pathway. This could be a mechanism contributing to the differential roles of these two pathways in fear learning (Lovett-Barron et al., 2014) and to the particular vulnerability of TA in stress (Kallarackal et al., 2013). While future studies are needed to determine whether changes in NPY + cell properties or inputs contribute to the impaired NPY release caused by stress, the regulatory mechanisms that control the firing of NPY + neurons and the release of endogenous NPY could be targeted to increase NPY levels in a spatially and temporally appropriate manner. 


\section{References}

Armstrong C, Krook-Magnuson E, Soltesz I (2012) Neurogliaform and ivy cells: a major family of nNOS expressing GABAergic neurons. Front Neural Circuits 6:23. CrossRef Medline

Bartley AF, Dobrunz LE (2015) Short-term plasticity regulates the excitation/inhibition ratio and the temporal window for spike integration in CA1 pyramidal cells. Eur J Neurosci 41:1402-1415. CrossRef Medline

Bezaire MJ, Soltesz I (2013) Quantitative assessment of CA1 local circuits: knowledge base for interneuron-pyramidal cell connectivity. Hippocampus 23:751-785. CrossRef Medline

Broussard JI, Yang K, Levine AT, Tsetsenis T, Jenson D, Cao F, Garcia I, Arenkiel BR, Zhou FM, De Biasi M, Dani JA (2016) Dopamine regulates aversive contextual learning and associated in vivo synaptic plasticity in the hippocampus. Cell Rep 14:1930-1939. CrossRef Medline

Chang YJ, Yang CH, Liang YC, Yeh CM, Huang CC, Hsu KS (2009) Estrogen modulates sexually dimorphic contextual fear extinction in rats through estrogen receptor beta. Hippocampus 19:1142-1150. CrossRef Medline

Cohen H, Liu T, Kozlovsky N, Kaplan Z, Zohar J, Mathé AA (2012) The neuropeptide Y (NPY)-ergic system is associated with behavioral resilience to stress exposure in an animal model of post-traumatic stress disorder. Neuropsychopharmacology 37:350-363. CrossRef Medline

Colmers WF, El Bahh B (2003) Neuropeptide Y and epilepsy. Epilepsy Curr 3:53-58. CrossRef Medline

Colmers WF, Lukowiak K, Pittman QJ (1987) Presynaptic action of neuropeptide Y in area CA1 of the rat hippocampal slice. J Physiol 383:285-299. CrossRef Medline

Colmers WF, Lukowiak K, Pittman QJ (1988) Neuropeptide Y action in the rat hippocampal slice: site and mechanism of presynaptic inhibition. J Neurosci 8:3827-3837. Medline

Day HE, Masini CV, Campeau S (2004) The pattern of brain c-fos mRNA induced by a component of fox odor, 2,5-dihydro-2,4,5-trimethylthiazoline (TMT), in rats, suggests both systemic and processive stress characteristics. Brain Res 1025:139-151. CrossRef Medline

Decressac M, Barker RA (2012) Neuropeptide Y and its role in CNS disease and repair. Exp Neurol 238:265-272. CrossRef Medline

Dekay JG, Chang TC, Mills N, Speed HE, Dobrunz LE (2006) Responses of excitatory hippocampal synapses to natural stimulus patterns reveal a decrease in short-term facilitation and increase in short-term depression during postnatal development. Hippocampus 16:66-79. CrossRef Medline

Dobrunz LE, Stevens CF (1999) Response of hippocampal synapses to natural stimulation patterns. Neuron 22:157-166. CrossRef Medline

Eaton K, Sallee FR, Sah R (2007) Relevance of neuropeptide Y (NPY) in psychiatry. Curr Top Med Chem 7:1645-1659. CrossRef Medline

Engin E, Treit D (2007) The role of hippocampus in anxiety: intracerebral infusion studies. Behav Pharmacol 18:365-374. CrossRef Medline

Fendt M, Endres T (2008) 2,3,5-Trimethyl-3-thiazoline (TMT), a component of fox odor-just repugnant or really fear-inducing? Neurosci Biobehav Rev 32:1259-1266. CrossRef Medline

Fuentealba P, Begum R, Capogna M, Jinno S, Márton LF, Csicsvari J, Thomson A, Somogyi P, Klausberger T (2008) Ivy cells: a population of nitric-oxideproducing, slow-spiking GABAergic neurons and their involvement in hippocampal network activity. Neuron 57:917-929. CrossRef Medline

Gong S, Zheng C, Doughty ML, Losos K, Didkovsky N, Schambra UB, Nowak NJ, Joyner A, Leblanc G, Hatten ME, Heintz N (2003) A gene expression atlas of the central nervous system based on bacterial artificial chromosomes. Nature 425:917-925. CrossRef Medline

Gong S, Doughty M, Harbaugh CR, Cummins A, Hatten ME, Heintz N, Gerfen CR (2007) Targeting Cre recombinase to specific neuron populations with bacterial artificial chromosome constructs. J Neurosci 27: 9817-9823. CrossRef Medline

Goosens KA (2011) Hippocampal regulation of aversive memories. Curr Opin Neurobiol 21:460-466. CrossRef Medline

Harro J (2006) CCK and NPY as anti-anxiety treatment targets: promises, pitfalls, and strategies. Amino Acids 31:215-230. CrossRef Medline

Heilig M (2004) The NPY system in stress, anxiety and depression. Neuropeptides 38:213-224. CrossRef Medline

Hirsch SJ, Regmi NL, Birnbaum SG, Greene RW (2015) CA1-specific deletion of NMDA receptors induces abnormal renewal of a learned fear response. Hippocampus 25:1374-1379. CrossRef Medline

Hoffman JR, Ostfeld I, Kaplan Z, Zohar J, Cohen H (2015) Exercise en- hances the behavioral responses to acute stress in an animal model of PTSD. Med Sci Sports Exerc 47:2043-2052. CrossRef Medline

Ibáñez-Sandoval O, Tecuapetla F, Unal B, Shah F, Koós T, Tepper JM (2011) A novel functionally distinct subtype of striatal neuropeptide $\mathrm{Y}$ interneuron. J Neurosci 31:16757-16769. CrossRef Medline

Isomura Y, Sirota A, Ozen S, Montgomery S, Mizuseki K, Henze DA, Buzsáki G (2006) Integration and segregation of activity in entorhinal-hippocampal subregions by neocortical slow oscillations. Neuron 52:871-882. CrossRef Medline

Kallarackal AJ, Kvarta MD, Cammarata E, Jaberi L, Cai X, Bailey AM, Thompson SM (2013) Chronic stress induces a selective decrease in AMPA receptor-mediated synaptic excitation at hippocampal temporoammonic-CA1 synapses. J Neurosci 33:15669-15674. CrossRef Medline

Karagiannis A, Gallopin T, Dávid C, Battaglia D, Geoffroy H, Rossier J, Hillman EM, Staiger JF, Cauli B (2009) Classification of NPY-expressing neocortical interneurons. J Neurosci 29:3642-3659. CrossRef Medline

Klausberger T, Somogyi P (2008) Neuronal diversity and temporal dynamics: the unity of hippocampal circuit operations. Science 321:53-57. CrossRef Medline

Kovac S, Walker MC (2013) Neuropeptides in epilepsy. Neuropeptides 47: 467-475. CrossRef Medline

Krook-Magnuson E, Luu L, Lee SH, Varga C, Soltesz I (2011) Ivy and neurogliaform interneurons are a major target of $\mu$-opioid receptor modulation. J Neurosci 31:14861-14870. CrossRef Medline

Ledoux VA, Smejkalova T, May RM, Cooke BM, Woolley CS (2009) Estradiol facilitates the release of neuropeptide $\mathrm{Y}$ to suppress hippocampusdependent seizures. J Neurosci 29:1457-1468. CrossRef Medline

Lovett-Barron M, Kaifosh P, Kheirbek MA, Danielson N, Zaremba JD, Reardon TR, Turi GF, Hen R, Zemelman BV, Losonczy A (2014) Dendritic inhibition in the hippocampus supports fear learning. Science 343:857863. CrossRef Medline

Madisen L, Mao T, Koch H, Zhuo JM, Berenyi A, Fujisawa S, Hsu YW, Garcia AJ 3rd, Gu X, Zanella S, Kidney J, Gu H, Mao Y, Hooks BM, Boyden ES, Buzsáki G, Ramirez JM, Jones AR, Svoboda K, Han X, et al (2012) A toolbox of Cre-dependent optogenetic transgenic mice for light-induced activation and silencing. Nat Neurosci 15:793-802. CrossRef Medline

Milstein AD, Bloss EB, Apostolides PF, Vaidya SP, Dilly GA, Zemelman BV, Magee JC (2015) Inhibitory gating of input comparison in the CA1 microcircuit. Neuron 87:1274-1289. CrossRef Medline

Nakamura NH, Akiyama K, Naito T (2011) Quantitative gene-expression analysis of the ligand-receptor system for classical neurotransmitters and neuropeptides in hippocampal CA1, CA3, and dentate gyrus. Hippocampus 21:1228-1239. CrossRef Medline

Neumann ID, Wegener G, Homberg JR, Cohen H, Slattery DA, Zohar J, Olivier JD, Mathé AA (2011) Animal models of depression and anxiety: what do they tell us about human condition? Prog Neuropsychopharmacol Biol Psychiatry 35:1357-1375. CrossRef Medline

Overstreet-Wadiche L, McBain CJ (2015) Neurogliaform cells in cortical circuits. Nat Rev Neurosci 16:458-468. CrossRef Medline

Pickel VM, Chan J, Veznedaroglu E, Milner TA (1995) Neuropeptide Y and dynorphin-immunoreactive large dense-core vesicles are strategically localized for presynaptic modulation in the hippocampal formation and substantia nigra. Synapse 19:160-169. CrossRef Medline

Price CJ, Cauli B, Kovacs ER, Kulik A, Lambolez B, Shigemoto R, Capogna M (2005) Neurogliaform neurons form a novel inhibitory network in the hippocampal CA1 area. J Neurosci 25:6775-6786. CrossRef Medline

Qian J, Colmers WF, Saggau P (1997) Inhibition of synaptic transmission by neuropeptide $\mathrm{Y}$ in rat hippocampal area CA1: modulation of presynaptic $\mathrm{Ca}^{2+}$ entry. J Neurosci 17:8169-8177. Medline

Ragu Varman D, Rajan KE (2015) Environmental enrichment reduces anxiety by differentially activating serotonergic and neuropeptide Y (NPY)ergic system in Indian Field Mouse (Mus booduga): an animal model of post-traumatic stress disorder. PLoS One 10:e0127945. CrossRef Medline

Reichmann F, Holzer P (2016) Neuropeptide Y: a stressful review. Neuropeptides 55:99-109. CrossRef Medline

Reichmann F, Wegerer V, Jain P, Mayerhofer R, Hassan AM, Fröhlich EE, Bock E, Pritz E, Herzog H, Holzer P, Leitinger G (2016) Environmental enrichment induces behavioural disturbances in neuropeptide Y knockout mice. Sci Rep 6:28182. CrossRef Medline

Remondes M, Schuman EM (2002) Direct cortical input modulates plasticity and spiking in CA1 pyramidal neurons. Nature 416:736-740. CrossRef Medline 
Remondes M, Schuman EM (2004) Role for a cortical input to hippocampal area CA1 in the consolidation of a long-term memory. Nature 431:699703. CrossRef Medline

Rosen JB, Asok A, Chakraborty T (2015) The smell of fear: innate threat of 2,5-dihydro-2,4,5-trimethylthiazoline, a single molecule component of a predator odor. Front Neurosci 9:292. CrossRef Medline

Sah R, Geracioti TD (2013) Neuropeptide Y and posttraumatic stress disorder. Mol Psychiatry 18:646-655. CrossRef Medline

Serova LI, Tillinger A, Alaluf LG, Laukova M, Keegan K, Sabban EL (2013) Single intranasal neuropeptide Y infusion attenuates development of PTSD-like symptoms to traumatic stress in rats. Neuroscience 236:298312. CrossRef Medline

Sheffield ME, Best TK, Mensh BD, Kath WL, Spruston N (2011) Slow integration leads to persistent action potential firing in distal axons of coupled interneurons. Nat Neurosci 14:200-207. CrossRef Medline

Smiałowska M, Wierońska JM, Domin H, Zieba B (2007) The effect of intrahippocampal injection of group II and III metobotropic glutamate receptor agonists on anxiety; the role of neuropeptide Y. Neuropsychopharmacology 32:1242-1250. CrossRef Medline

Somogyi J, Szabo A, Somogyi P, Lamsa K (2012) Molecular analysis of ivy cells of the hippocampal CA1 stratum radiatum using spectral identification of immunofluorophores. Front Neural Circuits 6:35. CrossRef Medline

Sørensen AT, Kanter-Schlifke I, Carli M, Balducci C, Noe F, During MJ, Vezzani A, Kokaia M (2008) NPY gene transfer in the hippocampus attenuates synaptic plasticity and learning. Hippocampus 18:564-574. CrossRef Medline

Sørensen AT, Nikitidou L, Ledri M, Lin EJ, During MJ, Kanter-Schlifke I, Kokaia M (2009) Hippocampal NPY gene transfer attenuates seizures without affecting epilepsy-induced impairment of LTP. Exp Neurol 215: 328-333. CrossRef Medline

Speed HE, Dobrunz LE (2009) Developmental changes in short-term facilitation are opposite at temporoammonic synapses compared to Schaffer collateral synapses onto CA1 pyramidal cells. Hippocampus 19:187-204. CrossRef Medline

Stockhorst U, Antov MI (2015) Modulation of fear extinction by stress, stress hormones and estradiol: a review. Front Behav Neurosci 9:359. CrossRef Medline

Sun HY, Lyons SA, Dobrunz LE (2005) Mechanisms of target-cell specific short-term plasticity at Schaffer collateral synapses onto interneurones versus pyramidal cells in juvenile rats. J Physiol 568:815-840. CrossRef Medline
Sun HY, Bartley AF, Dobrunz LE (2009) Calcium-permeable presynaptic kainate receptors involved in excitatory short-term facilitation onto somatostatin interneurons during natural stimulus patterns. J Neurophysiol 101:1043-1055. CrossRef Medline

Szabo A, Somogyi J, Cauli B, Lambolez B, Somogyi P, Lamsa KP (2012) Calcium-permeable AMPA receptors provide a common mechanism for LTP in glutamatergic synapses of distinct hippocampal interneuron types. J Neurosci 32:6511-6516. CrossRef Medline

Tricoire L, Pelkey KA, Daw MI, Sousa VH, Miyoshi G, Jeffries B, Cauli B, Fishell G, McBain CJ (2010) Common origins of hippocampal Ivy and nitric oxide synthase expressing neurogliaform cells. J Neurosci 30:21652176. CrossRef Medline

Tricoire L, Pelkey KA, Erkkila BE, Jeffries BW, Yuan X, McBain CJ (2011) A blueprint for the spatiotemporal origins of mouse hippocampal interneuron diversity. J Neurosci 31:10948-10970. CrossRef Medline

Tu B, Timofeeva O, Jiao Y, Nadler JV (2005) Spontaneous release of neuropeptide $\mathrm{Y}$ tonically inhibits recurrent mossy fiber synaptic transmission in epileptic brain. J Neurosci 25:1718-1729. CrossRef Medline

van den Pol AN (2012) Neuropeptide transmission in brain circuits. Neuron 76:98-115. CrossRef Medline

van den Pol AN, Yao Y, Fu LY, Foo K, Huang H, Coppari R, Lowell BB, Broberger C (2009) Neuromedin B and gastrin-releasing peptide excite arcuate nucleus neuropeptide $\mathrm{Y}$ neurons in a novel transgenic mouse expressing strong Renilla green fluorescent protein in NPY neurons. J Neurosci 29:4622-4639. CrossRef Medline

Vollmer LL, Schmeltzer S, Schurdak J, Ahlbrand R, Rush J, Dolgas CM, Baccei ML, Sah R (2016) Neuropeptide Y impairs retrieval of extinguished fear and modulates excitability of neurons in the infralimbic prefrontal cortex. J Neurosci 36:1306-1315. CrossRef Medline

Wierenga CJ, Müllner FE, Rinke I, Keck T, Stein V, Bonhoeffer T (2010) Molecular and electrophysiological characterization of GFP-expressing CA1 interneurons in GAD65-GFP mice. PLoS One 5:e15915. CrossRef Medline

Yamamoto S, Morinobu S, Takei S, Fuchikami M, Matsuki A, Yamawaki S, Liberzon I (2009) Single prolonged stress: toward an animal model of posttraumatic stress disorder. Depress Anxiety 26:1110-1117. CrossRef Medline

Zhang X, Wang B, Jin J, An S, Zeng Q, Duan Y, Yang L, Ma J, Cao X (2014) Early deprivation reduced anxiety and enhanced memory in adult male rats. Brain Res Bull 108:44-50. CrossRef Medline

Zucker RS, Regehr WG (2002) Short-term synaptic plasticity. Annu Rev Physiol 64:355-405. CrossRef Medline 